\title{
Concentraciones fosilíferas del Kimmeridgiano Superior en Mazapil, Zacatecas, México: Tafonomía e interpretación paleoambiental
}

\author{
Iriliana López-Caballero, Federico Olóriz, Ana Bertha Villaseñor
}

Iriliana López-Gaballero

irilianalc@yahoo.com.mx

Posgrado en Ciencias de la Tierra, Sede Instituto de Geología, UNAM, Ciudad Universitaria, C.P. 04510, CDMX, México.

\section{Federico Olóriz}

Departamento de Estratigrafía y Paleontología, Facultad de Ciencias, Universidad de Granada, Av. Fuentenueva s/n, C.P. 18002, Granada, España.

\section{Ana Bertha Villaseñor}

Departamento de Paleontología, Instituto de Geología, UNAM, Giudad Universitaria, G.P. 04510, CDMX, México.

BOL. SOC. GEOL. MEX. 2018

VOL. 70 NO. 1

P. $241-280$

http://dx.doi.org/10.18268/BSGM2018v70nla14

Manuscrito recibido: Julio 15, 2017

Manuscrito corregido: Agosto 18, 2017

Manuscrito aceptado: Agosto 22, 2017

\section{RESUMEN}

Como aproximación preliminar al estudio detallado de concentraciones fosilíferas en el Jurásico Superior de México, se analizan las registradas en una sucesión de 410 $\mathrm{cm}$ de espesor de la Formación La Caja, perteneciente al Kimmeridgiano tardío, la cual aflora en el Cañón de San Matías. Mazapil, Zacatecas.

Las observaciones litoestratigráficas, sedimentológicas, paleontológicas, bioestratigráficas y tafonómicas se realizaron estrato a estrato con resolución centimétrica. El estudio taxonómico y bioestratigráfico se centró en las asociaciones de macroinvertebrados, esencialmente ammonites. El análisis tafonómico se realizó sobre 1175 restos cuya composición responde a la de comunidade neríticas (ammonites $53 \%$, aptychi $27 \%$, bivalvos $18 \%$ y gasterópodos $2 \%$ que se depositaron en profundidades menores que las de implosión para las carcasas de ammonites.

En ámbito de plataforma sin evidencias de relieves pronunciados, se interpreta un contexto eco- sedimentario de baja energía (floatstone-wackestone de bioclastos y wackeston de radiolarios; existen parches locales de packstone), con depósito de limolitas incipiente e irregularmente calcáreas asociadas a un ambiente de plataforma sin evidencias de relieves pronunciados. Son características la ausencia de superficies de erosión expresivas, deslizamientos sinsedimentarios, aportes exóticos, y estructuras sedimentaria inequívocamente relacionadas con oleaje, así como el predominio de laminaciones paralelas y/o suavement oblicuas. Las condiciones ecológicas incluyeron fondos disaeróbicos-poikiloaeróbicos con escaso registro de bentos in situ, y ferruginización frecuente relacionada con concentraciones de materia orgánica, así como inestabilidades en la columna de agua que afectarían a las comunidades de organismos pelágicos y bentónicos generando incrementos en la exportación de restos al fondo.

Las concentraciones fosilíferas registradas son más expresivas hacia la base y techo de los estratos, son discontinuas y su configuración macroscópica responde a la de pavimentos y capas de conchas (shell beds). Se interpretan como eventitas distales resultantes de procesos con energía efectiva variable (huracanes, tormentas, corrientes de fondo ligadas a tormentas, aventamientos), cuya incidencia alcanzó sectores proximales de la plataforma externa en torno al nivel de base de tormentas. Secuencias de redepósito incompletas se relacionan con eventos de mayor energía efectiva y sobreimposición de horizontes. El patrón de la secuencia de redepósito tipo responde a eventos energéticos, disipación progresiva pero rápida de la ener gía, y retorno a condiciones eco-sedimentarias normale para el sector según el registro estratigráfico.

La dinámica eco-sedimentaria propuesta para la sucesión estudiada en el perfil Cañón de San Matías responde a rupturas de equilibrio ambiental con periodos de recurrencia de rango inferior al de la resolución bioestratigráfica en ámbito de plataforma, sin evidencias de relieve próximos, ni de la existencia de ruptura de plataforma n talud continental en el área, durante el intervalo estudiado del Kimmeridgiano tardío.

Palabras clave: Concentraciones fosilíferas, macroinvertebrados, eventitas, Jurásico Superior, Kimmeridgiano, México.

\section{ABSTRACT}

A $410 \mathrm{~cm}$ thick succession of late Kimmeridgian deposits belonging to the La Caja Fm. has been analyzed in the San Matias Canyon as preliminary approach to the study of fossil concentrations in the Upper Furassic of Mexico.

Lithostratigraphic, sedimentologic, taxonomic, biostratigraphic and taphonomic observations based on a bed-by-bed sampling with centimeter scale resolution. Taxonomic and biostratigraphic analyses focused on macroinvertebrate assemblages, mainly ammonites. The taphonomic analysis applied to 1175 fossil remains of neritic communities (ammonites $53 \%$, aptychi 27 $\%$, bivalves $18 \%$ and gastropods $2 \%$ ), accumulated in depths lesser than those estimated for implosion of ammonite carcasses. Within a shelf-area without evidence of high-irregular seabeds, an eco-sedimentary context of low energy agrees with depositional conditions resulting in lithofacies of floatstone-wackestone of bioclasts and wackestone of radiolaria, together with local patches of packstone and the intercalation of calcareous siltstone. In addition, low energy conditions are in accordance with the absence of expressive erosion surfaces, synsedimentary sliding, exotic clasts, and sedimentary structures typically related to wave action, as well as with the common occurrence of parallel and/or subtle oblique laminations. Ecological conditions included disaerobic-poikiloaerobic seabeds with rare record of benthos in situ, common ferruginization related to organic matter-rich sediments, and water column instabilities affecting pelagic and benthic communities resulting in increased accumulation of skeletals remains on the seabed.

The recorded fossiliferous concentrations are more evident to the bottom and top surfaces of beds, they are discontinuous, and their macroscopic biofabric corresponds to pavements and shell beds. These fossil-rich horizons are interpreted as distal eventites resulting from turbulence events of variable effective energy hurricanes, storms, storm-forced bottom currents, and winnowing), the influence of which reached proximal sectors of the outer shelf at depths close to the storm wave base. Incomplete sequences related to reworking are interpreted as resulting from events of higher-than-background effective energy and over-imposition of depositional horizons. The pattern of the type sequence of re-deposition related to the succession of higher-than-background energy events, progressive but rapid dissipation of energy, and the return to background eco-sedimentary conditions.

The eco-sedimentary dynamics proposed for the succession analyzed at the San Matias Canyon, Mazapil, Zacatecas, indicates pulses of paleoenvironmental instability within a neritic shelf, and with recurrence periods shorter than the range of biostratigraphic resolution. No evidence of high-irregular seabeds has been found in the surrounding area nor the occurrence of the shelf-break and slope in the area during the investigated stratigraphic interval of late Kimmeridgian age.

Keyzords: Shell concentrations, macroinvertebrates, eventites, Upper Jurassic, Kimmeridgian, Mexico. 


\section{Introducción}

El avance del conocimiento bioestratigráfico y las correlaciones en el Jurásico Superior de México exige muestreos estrato a estrato, así como la referencia precisa de los horizontes de procedencia del material recolectado (Villaseñor et al., 1995). Villaseñor et al. (2012) basándose en información de campo y más de 20 años de investigación efectuada con muestreos estrato a estrato, han reportado diferentes asociaciones de ammonites para establecer una propuesta biozonal para el Jurásico Superior (Oxfordiano-Kimmeridgiano-Tithoniano) del norte-centro y sur de México. La diferencia de esta propuesta respecto a otras realizadas con anterioridad (p.ej., Burckhardt, 1930; Imlay, 1939; Cantú-Chapa, 1969, 1971, 1979, 1980, 1984) radica en la identificación de la discontinuidad del registro bioestratigráfico (introducida por Olóriz, 1987 de manera preliminar; ya destacada por Villaseñor, 1991; Callomon, 1992; Olóriz, 1992), la precisión de la información bioestratigráfica y el reconocimiento de asociaciones nuevas con gran valor biocronoestratigráfico y de correlación a diversa escala. Estos trabajos han abarcado localidades que se consideran clásicas para el estudio de asociaciones de macroinvertebrados del noreste de México, centrándose en el análisis de la fauna de ammonites y bivalvos del Jurásico Superior, si bien las publicaciones sobre bentónicos han sido limitadas (De la Mora et al., 1999a, 1999b, 2000). En paralelo, se han abordado algunos aspectos paleobiogeográficos, tafonómicos y paleoecológicos (p.ej., Schumann, 1985, 1988; Olóriz, 1987, 1992; Olóriz et al., 1988, 1990, 1997, 2003a; Villaseñor, 1991; Villaseñor et al., 1991; Michalzik y Schumann, 1994; De la Mora et al., 2000, Zell et al., 2014; Zell y Stinnesbeck, 2016; Olóriz y Villaseñor, 2017).

El objetivo de este trabajo es el estudio de las acumulaciones fosilíferas del Kimmeridgiano terminal en la Región de Mazapil, Zacatecas, que representan un tipo de registro recogido bajo diferentes denominaciones en la bibliografía: lumachelles o lumaquelas (Burckhardt, 1930; Schumann, 1988;
Adatte et al., 1993; Jank et al., 2006; Hara y Taylor, 2009; Omaña et al., 2012), coquinite, coquinitas o coquinas (Aigner et al., 1978; Schumann, 1985; Kidwell, 1991; Velasco-Segura, 2005; Buchy et al., 2006; Buchy, 2010; Zell et al., 2014), horizontes de acumulación de fósiles (Velasco-Segura, 2005); condensed beds o capas y niveles condensados (Verma y Westermann, 1973; Villaseñor, 1991; Olóriz et al., 1996; 1999; López-Caballero, 2009), shell beds o shell and/or fossil concentrations (Kidwell y Aigner, 1985; Kidwell, 1986, 1991; Cooper, 1997; Brett et al., 2008; Dattilo et al., 2012). En los trabajos sobre acumulaciones fosilíferas en México se explican de manera breve los mecanismos de acumulación de los niveles con gran concentración fosilífera, y no se ha realizado un análisis detallado sobre mecanismos y procesos involucrados en la formación de estos horizontes.

Para poder realizar el análisis de las concentraciones fosilíferas es importante evaluar las diferentes características paleontológicas, tafonómicas y sedimentológicas, ya que son los factores que inciden y controlan su formación (Brandt, 1989; Fürsich, 1978; Fürsich y Oschmann, 1993; Kidwell et al., 1986), también condicionada sin duda por la paleogeografía y características paleoambientales locales.

Como la composición taxonómica de la asociación fósil registrada es parte inherente de la estructura de la comunidad que, mayoritariamente, proporciona los restos potencialmente preservables y, por tanto, sus características hidrodinámicas de cara a la acumulación, se procederá a un estudio taxonómico y a la caracterización de las asociaciones fósiles colectadas. Además, se considerará la conservación de los restos y su afectación por procesos bioestratinómicos que culminan con la exposición post-mortem en el fondo marino, enterramiento definitivo, y la posterior diagénesis temprana como bioclastos incluidos en la zona tafonómicamente activa.

Se ha destacado que las características tafonómicas de los restos fósiles, más que reflejar los hábitos de las especies, muestran el proceso post-mortem, especialmente en sus fases finales (Davies et al., 1989; 
Fürsich y Oschmann, 1993). Entre otros factores que intervienen en la composición de la asociación fósil registrada, son de especial interés el retrabajamiento (reworking), incluyendo resedimentación y reelaboración sensu Fernández-López y Gómez, 1991), el porcentaje de pérdida de partes duras, y el contenido temporal del horizonte fosilífero en términos de promediado temporal o time-averaging (Fürsich, 1978; Kidwell y Aigner, 1985; Kidwell et al., 1986). Esa información resulta crucial para determinar el nivel adecuado de interpretación de la asociación fósil registrada en términos paleoeocológicos y/o ecoestratigráficos.

Para poder caracterizar más fielmente las concentraciones de conchas, Kidwell (1991) propuso una clasificación en cuatro tipos genéticamente definidos:

1. Concentraciones episódicas (Event-concentrations), las cuales tienen la escala de una sola o varias láminas hasta una o pocas capas, registrando uno o varios episodios breves de concentración de conchas con espesor limitado.

2. Concentraciones compuestas o concentraciones multi-episódicas (Composite or Multiple-event concentrations), registradas como capas de cuerpos o paquetes sedimentarios y facies bioclásticas a escala de cuenca o subcuenca. Las historias de depósito son más complejas, más duraderas, y registran la acreción, so breimposición, incluso mezcla de múltiples generaciones y/o eventos de concentración. La concentración resultante muestra un espesor equivalente al promedio de los estratos correlacionables, o algo mayor.

3. Concentraciones hiatales o condensadas (Hiatal or condensed concentrations), son acumulaciones complejas, similares a las de tipo 2 pero desarrolladas in situ y con menor espesor que los intervalos estratigráficos equivalentes que resultan de condiciones de depósito relacionadas con la dinámica ambiental normal. El cuerpo sedimentario resultante es un intervalo condensado, usualmente referido como condensación estratigráfica. Con frecuencia suele considerarse una tasa baja de acumula- ción como el factor desencadenante del intervalo condensado, pero en este y otros casos, una interpretación precisa de la condensación debería tener en cuenta el contexto genético planteado por Gómez y Fernández-López (1994).

4. Concentraciones de retrabajamiento recurrente y prolongado (Lag-concentrations), las cuales son concentraciones delgadas de restos con alto potencial de preservación, asociadas a superficies estratigráficas que expresan discontinuidades relevantes. Las conchas son repetidamente exhumadas y retrabajadas, generándose concentraciones ligadas a procesos de ámbito regional.

La evaluación de la escala física, la geometría, la complejidad interna y el contexto estratigráfico aporta evidencias que ayudan a interpretar el tipo de concentración objeto de estudio. Las concentraciones fosilíferas ofrecen características tafonómicas de espesor, biofábrica, y composición taxonómica que son esenciales para determinar la variedad de procesos bióticos y abióticos que pueden informar acerca de los agentes involucrados en la formación del tipo de concentración (Kidwell et al., 1986; Kidwell, 1991; Fürsich y Oschmann, 1993).

Conviene recordar que el termino estratigráfico "condensación" no debería utilizarse como sinónimo para "concentración". Una concentración de conchas no necesariamente involucra determinado tipo de condensación (estratigráfica, sedimentaria, tafonómica sensu Gómez y Fernández-López, 1994). Según Fernández-López (1984) y Fernández-López y Gómez (1991), la condensación puede ser resultado de la interacción de diversos factores, como el decremento en las tasas de sedimentación y de acumulación, así como de la mezcla de asociaciones fósiles de distinta edad.

\subsection{ESTUDIOS PREVIOS SOBRE GONGENTRAGIONES FOSILÍFERAS DEL JURÁSICO SUPERIOR EN EL NORESTE DE MÉXICO}

Los niveles con concentraciones de fósiles, a 
pesar de ser estratigráficamente relevantes y reconocibles en diversos afloramientos del Jurásico Superior marino del noreste de México, particularmente en las formaciones La Caja y La Casita, han sido escasamente estudiados, incluso algunos de ellos sólo mencionados.

Los primeros en señalar la presencia de niveles con grandes acumulaciones fosilíferas fueron Verma y Westermann (1973) en su estudio bioestratigráfico del Jurásico Superior de varias localidades en la Sierra de Catorce, San Luis Potosí, en afloramientos de la Formación La Caja. Estos autores refieren acumulaciones fosilíferas con un espesor de 0.60 m como "Virgatosphinctinae beds" en el Tithoniano medio. Además, señalan que "The specimens of the Virgatosphinctinae beds give the appearance of having been reworked and the assemblage of this horizon may, therefore, be "condensed" (p. 142), e interpretan que debido a que "bivalves and brachiopods were extremely abundant in the Virgatosphinctinae beds and that at least these beds originated in shallow waters" (p. 160).

Schumann (1985 y 1988) interpretó la paleoecología de niveles concrecionales con abundante fauna de ammonites, bivalvos, madera y otros restos de plantas basado en el análisis de facies y de la biota del límite Kimmeridgiano superior-Tithoniano de la Formación La Casita en la región de Iturbide, Nuevo León, Matehuala y Dr. Arroyo, San Luis Potosí y Gd. Victoria, Tamaulipas. Cabe señalar que ninguno de los taxones de ammonites que reconoció (p. ej. Idoceras duranguense, Haploceras fialar, Aspidoceras cf. haupti y Aulacosphinctoides sp. 1) se relaciona con el límite mencionado. En la interpretación paleoambiental observó que la falta de organismos epi y endobentónicos, junto con la litología, indicarían un ambiente pobre en oxígeno durante periodos largos, en donde la presencia de concentraciones del bivalvo Aulacomyella se debió a su carácter pseudoplanctónico - fijado a madera flotante o a hipotéticas algas - y a su posterior depósito post-mortem. Por lo tanto, excluyó que dicho bivalvo formara parte de la biocenosis de fondo, de manera que los organismos marinos reconocidos se concentrarían esencialmente en las capas superiores de la columna de agua. Asimis- mo, explicó la abundancia de fósiles en las concreciones como resultado de eventos de alta energía - huracanes - que ocasionaron el transporte y acumulación de material de diferentes tamaños, y el consecuente acomodo de las conchas en horizontes especialmente enriquecidos en restos. La presencia de rocas fosforíticas la relacionó con una profundidad máxima de $300 \mathrm{~m}$ en el período transgresivo entre el Kimmeridgiano y el Tithoniano. No obstante, siendo acertada especialmente en aspectos paleoecológicos, más que sedimentológicos, su aproximación resulta generalizada en tanto que no menciona si las concentraciones muestran diferencias de fábrica y/o edad, sin aclarar e interpretar su distribución en una sección de más de $300 \mathrm{~m}$ de espesor.

Olóriz (1987), basado en el estudio de diversos afloramientos en el área Cuencamé y Sierra de Symon en Durango y área de Mazapil en Zacatecas, hizo una propuesta de modelo eco-evolutivo para los registros de ammonoideos en materiales del Jurásico Superior del noreste de México. En particular, y en relación con tema del presente trabajo, mencionó que: "el relevo de la fauna más característica en los niveles inferiores coincide con el cambio en las condiciones ambientales que hoy deducimos por la presencia del nivel de caliza condensada" (p. 236); más adelante y basado en estudios mineralógicos en los afloramientos de Cuencamé, Durango (publicados después en Olóriz et al., 1988), concluyó que "la ausencia de trazas aparentes de remoción, el carácter condensado y su distribución regional, interpretó este nivel como una evidencia de un máximo transgresivo con el consiguiente efecto de caída en la tasa de sedimentación detrítica en áreas que han adquirido una posición comparativamente distal debido a la elevación del nivel del mar" (p. 237). Esta interpretación fue posteriormente confirmada por Olóriz (1992).

Olóriz et al. (1988) mediante estudios mineralógicos e isotópicos analizan las intercalaciones yesíferas, y lo que denominaron "caliza arcillosa negra", que afloran en el Anticlinal de Palotes en la región de Cuencamé, Durango. Respecto a los valores 
isotópicos de $\delta^{18} \mathrm{O}$ y $\delta^{13} \mathrm{C}$ de la caliza, señalan que son concordantes con valores característicos de las calizas marinas. $\mathrm{Al}$ hacer las consideraciones paleoecológicas señalan que la "caliza arcillosa negra" pudiera representar pulsos transgresivos que no necesariamente provocarían un aumento significativo en la profundidad.

Villaseñor (1991) en el área de la Sierra de Mazapil, Zacatecas (área estudiada por Burckhardt, 1906a y 1906b), reconoce un estrato que denominó "caliza negra", con gran cantidad de fósiles (ammonites y bivalvos); en los gráficos lo refiere como nivel condensado, asignándole una edad correspondiente al Kimmeridgiano superior. Esta autora caracterizó el área de estudio como una plataforma somera con profundidades que van desde 30 a $100 \mathrm{~m}$, presentando un alto grado de endemismo a nivel especifico, por lo que supuso que la plataforma estuvo en ocasiones subdividida y con conexión restringida respecto a las aguas oceánicas, permitiendo así casos de evolución in situ. Sin presentar una interpretación particular de su "caliza negra", Villaseñor (1991) mencionó que las variaciones faunísticas reconocidas en el perfil estudiado pudieron ser la respuesta a cambios en las condiciones de depósito, a diferencias ambientales y ecológicas muy probablemente relacionadas con fases episódicas de mejora en las conexiones con masas de agua oceánicas.

Olóriz et al. (1996, 1999) estudiaron un afloramiento previamente reconocido por Verma y Westermann (1973) en el área de Real de Catorce, San Luis Potosí, y además de precisar la edad de la "Capas de Virgatosphinctinae" como del Tithoniano inferior (Cron Semiforme-Verruciferum), mencionaron que dicha acumulación de restos resultó de una condensación sedimentaria y estratigráfica relacionada con un evento de inundación en el área.

Olóriz et al. (1997) abordaron el estudio de afloramientos con niveles que contenían concentraciones fosilíferas, las cuales refirieron como "calizas condensadas", presentando diferente edad, desde la parte más tardía del Kimmeridgiano temprano, el Kimmeridgiano tardío y la parte más tardía del Tithoniano temprano. De particular interés es la "caliza condensada" ubicada en Cuencamé, Durango, correspondiente al Kimmeridgiano Superior. Estos autores interpretaron que la composición dependió de las condiciones sedimentarias y cambios en las condiciones hidrodinámicas de las corrientes en las capas superiores, como respuesta a pulsos transgresivos que favorecieron el incremento en carbonatos. Así, la condensación sin incidencia bioestratigráfica se relacionó con el enriquecimiento en carbonatos. Para la "caliza condensada fosforítica" identificada en Real de Catorce, San Luis Potosí, en la que reconocieron diversos biohorizontes del Tithoniano Inferior sin distorsión bioestratigráfica, señalaron cambios en la litología, presentándose limolitas arenosas y limolitas sobreyacidas por calizas fosforíticas arcillosas ricas en ammonites, lo que refleja un contexto de pulso(s) transgresivo(s) que acentuó el evento de condensación estratigráfica.

Velasco-Segura (2005) realizó un estudio en el Perfil denominado Sierra El Jabalí y Perfil Gómez Farías, ambos localizados a $60 \mathrm{~km}$ al sur de la Ciudad de Saltillo, Coahuila, donde identificó dos acumulaciones de fósiles (= coquinas, ibid. p. 10) en su Unidad I, con vertebrados marinos, bivalvos, amonitas, belemnites, "ostras" (comillas de los autores dado que parecen tratarse por separado de los bivalvos previamente mencionados) y restos de madera. Este autor consideró que quizá se tratase de horizontes de condensación autóctonos, depositados cerca del borde de la plataforma, acumulados durante un evento transgresivo-regresivo, y descartó la posibilidad que fuesen depósitos de tormenta ya que no observó retrabajamiento, las relaciones de las superficies de estratificación son concordantes, y no hay evidencias de imbricación o depósito caótico (ibid. p. 101). La edad asignada a dichas acumulaciones fósiles resulta ambigua, ya que únicamente en su figura 56 señaló que se encuentran en el Tithoniano.

López-Caballero (2009) estudió el afloramiento denominado Puerto Piñones-1 al sur de la Ciudad de Saltillo, Coahuila, identificando dos intervalos carbonatados, condensados, de distinta edad: (i) de 
$1 \mathrm{~m}$ de espesor y edad Kimmeridgiano tardío, en el que se observaron abundantes conchas de bivalvos, gran cantidad de aptychi y muy escasos ammonites aplastados; (ii) de 0.3 a $0.5 \mathrm{~m}$ de espesor y edad Tithoniano tardío, con ammonites depositados con orientación diversa, así como escasos bivalvos de gran tamaño mal conservados. La autora proporcionó datos tafonómicos de estos niveles y diferenció una tafofacies (Tafofacies 3, ibid. p. 123) que interpretó como resultante de condiciones de "ambiente de plataforma externa, donde las condiciones ambientales se modificaron, el tirante de agua aumentó, la energía del ambiente disminuyó, la distribución de los nutrientes experimentó variaciones, etc.; reflejándose en el contenido fósil, el cual es propio de ambientes más profundos o distales" (ibid. p. 125).

Posteriormente, Buchy (2010) y Buchy et al. (2013), al estudiar los vertebrados registrados en la denominada capa de coquina (ibid. 2010, p. 149) de $1.5 \mathrm{~m}$ de espesor identificada por Velasco-Segura (2005) en Gómez Farías, Coahuila, la consideraron una concentración tipo Lagerstätte debido a su riqueza en vertebrados marinos, sugiriendo que el depósito de la mencionada capa se formó en un ambiente somero submareal, con fondo lodoso por debajo del efecto de tormenta, como resultado de la reducción en la tasa de sedimentación y condensación, posiblemente debido a una transgresión.

Zell et al. (2014) estudiaron nuevamente la localidad de Gómez Farias, Coahuila, de Velasco-Segura (2005), y analizaron detalladamente la acumulación fósil denominada como coquinite (ibid. p. 91). En ella destacaron su composición inusual con abundantes vertebrados (reptiles marinos) e invertebrados marinos (ammonites, aptychi y bivalvos). Le asignaron una edad de Kimmeridgiano, Zona Beckeri, y fue interpretada como una concentración resultante de factores biogénicos y físicos. La concentración biogénica sería el resultado del aumento en la productividad debido a surgencias (upwellings) de aguas enriquecidas en nutrientes en el tirante de agua y en la interfase sedimento agua. Los bivalvos se desarrollaron du- rante periodos cortos de incremento en la oxigenación, al tiempo que reptiles marinos y ammonites poblaban la columna de agua (Zell et al., 2014, p. 104). La concentración física de granos de fosfato y fósiles fue resultado de eventos de tormenta y corrientes de fondo (concentraciones hidráulicas sensu Rogers y Kidwell, 2007) además del régimen transgresivo que redujo las tasas de sedimentación neta, favoreciendo el episodio de condensación.

Teniendo en cuenta el marco de referencia expuesto, en este trabajo se caracterizan detalladamente las concentraciones fosilíferas del Kimmeridgiano Superior de una sección estratigráfica ubicada en la Sierra de Santa Rosa en la región de Mazapil, Zacatecas, mediante un análisis minucioso del contenido taxonómico y las características tafonómicas de los restos que conforman las concentraciones, así como rasgos petrográficos y sedimentológicos de la roca encajante, con el fin de profundizar con la interpretación paleoambiental.

\subsection{GONTEXTO GEOGRÁFICO Y GEOLÓGICO}

El área de estudio se localiza, en la Sierra Madre Oriental próxima al límite norte de la Mesa Central (Nieto-Samaniego et al., 2005), que configura una de las principales cordilleras del país, directamente ligada a un grupo de altos estructurales relacionados con la apertura del Golfo de México, controlando las condiciones de depósito prácticamente durante todo el Mesozoico. Posteriormente, la Orogenia Laramide generaría las estructuras plegadas que conforman el noreste mexicano $(\mathrm{Pa}-$ dilla y Sánchez, 1982, 1986; Goldhammer et al., 1991; Goldhammer, 1999).

Durante el Triásico, la etapa de rifting e inicio de la segmentación de la Pangea se caracterizó por el desarrollo de sistemas de grabens y horsts. Ejemplos de zonas deprimidas serán las cuencas de Sabinas, de Maverick, la denominada Cuenca Mexicana o Geosinclinal Mexicano, la Guenca de Magascatzin, y los Canales de Chihuahua y Monterrey, todas ellas muy probablemente limitadas por fallas con desplazamiento lateral izquierdo. Ejemplos de zonas elevadas son altos estructurales como el 
Bloque o Isla de Coahuila, las islas de la Mula y de Monclova, el Bloque del Burro Peyotes y el Archipiélago de Tamaulipas. Respecto a la influencia de los altos topográficos en la sedimentación, el ejemplo de la Península de Coahuila se ha relacionado con el depósito de conglomerados, areniscas y limolitas de la Formación La Casita, como evidencia de ambientes deltaicos y de plataforma interna (Michalzik, 1988; Goldhammer et al., 1991; Salvador, 1991; Goldhammer, 1999; Zell et al., 2014), mientras que depósitos contemporáneos de margas, limolitas y fosforitas de la Formación La Caja al Sur de Monterrey y Saltillo reflejarían ambientes más distales en la plataforma interna y externa (Michalzik, 1988; Michalzik y Schumann, 1994; Olóriz et al., 1997; Buchy et al., 2006; Zell et al., 2014.

Durante el Triásico tardío la apertura del Golfo de México fue acompañada de la expansión del piso oceánico en el Golfo de México (Imlay, 1941; Buffler y Sawyer, 1985; Goldhammer, 1999; Olóriz et al., 2003b y referencias incluidas; Padilla y Sánchez, 2007; Villaseñor et al., 2015; Martini y Ortega-Gutiérrez, 2016). En el Oxfordiano temprano se produjo la transición a la fase de drifting (Goldhammer et al., 1991; Goldhammer, 1999; González-Sánchez et al., 2007, Martini y Ortega-Gutiérrez, 2016). En ese contexto, la irregularidad del fondo marino fue localmente acentuada y relacionada con tectónica de bloques (para el noreste de México véase Goldhammer, 1999; Zell et al., 2014). Olóriz (1992) y Buchy (2008) interpretaron que la sedimentación marina durante el Jurásico tardío fue afectada por inestabilidad tectónica regional en interacción con variaciones en el nivel del mar. La irregularidad de los fondos y la diferenciación en las condiciones eco-sedimentarias han sido aludidas para explicar diferencias en el registro de asociaciones de ammonites y la incidencia considerable de endemismo (Olóriz, 1992; Olóriz et al., 1997; Villaseñor et al., 2000, 2012). Aún hacia el final del Jurásico las conexiones marinas han sido consideradas restringidas tanto al este como al oeste por Zell et al. (2014). Estos autores interpretaron que los escasos registros de calpio- nélidos de la parte más temprana del Tithoniano tardío evidencian la persistencia de desconexiones temporales e irregulares entre áreas actualmente aflorantes en México y las de referencia en Europa y en el ámbito del Pacífico; posibles barreras podrían relacionarse con el alto topográfico de Florida al este y el Arco Magmático de Sinaloa al oeste. Complementariamente, diferencias en las características de las masas de agua podrían acentuar o, alternativamente, ser los factores más directamente involucrados en las desconexiones ecológicas para invertebrados marinos (Myczyński et al., 1998; Olóriz et al., 2000, 2008; López-Palomino et al., 2006; Villaseñor y Olóriz, 2009; Villaseñor et al., 2015; Moliner et al., 2016). Una reconstrucción del contexto paleoambiental regional puede encontrarse en Olóriz y Villaseñor (2017).

\subsubsection{FORMACIÓN LA CAJA EN EL ÁREA DE MAZAPIL, ZACATECAS}

La Formación La Caja fue definida por Imlay (1938), designando como localidad tipo la Vereda del Quemado, en el flanco meridional de la Sierra de la Caja, al norte de Mazapil, Zacatecas. Materiales pertenecientes a la Formación La Caja fueron considerados de edad Kimmeridgiano-Tithoniano (Burckhardt, 1906b; Rogers et al., 1961; Córdoba-Méndez, 1964; Verma y Westermann, 1973); posteriormente se ha reconocido su extensión al Berriasiano inferior (Villaseñor 1991; Olóriz et al., 1996; De la Mora et al., 1999a, 1999b, 2000; Olóriz et al., 1999; Villaseñor et al., 2000, 2012; Barboza-Gudiño et al., 2004; Eguiluz de Antuñano et al., 2012; Zell et al., 2013, 2016). López-Palomino (2015) aportó una revisión de la información existente de la Formación La Caja, destacando variaciones litológicas regionales y las subdivisiones propuestas (Verma y Westermann, 1973; Pessagno et al., 1999). Litologías reconocidas son calizas y margas de estratificación delgada, calcarenitas, areniscas bituminosas, limolitas calcáreas, lutitas con escaso contenido en carbonatos, fosforitas y horizontes con concreciones calcáreas y calcáreo-fosforíticas de dimensiones centimétricas a métricas. Intercalaciones de horizontes silí- 
ceos son más frecuentes en la parte superior. El contenido macropaleontológico incluye cefalópodos, gasterópodos, pelecípodos, braquiópodos, serpúlidos, peces, reptiles y restos vegetales, incluidos fragmentos leñosos.
La Formación La Caja aflora en la parte central, norte y noreste de la Cuenca de la Mesa Central, con espesores de pocos metros a pocos cientos de metros. El área de estudio (Figura 1) se encuentra en la región tipo, en la Sierra de Santa Rosa.

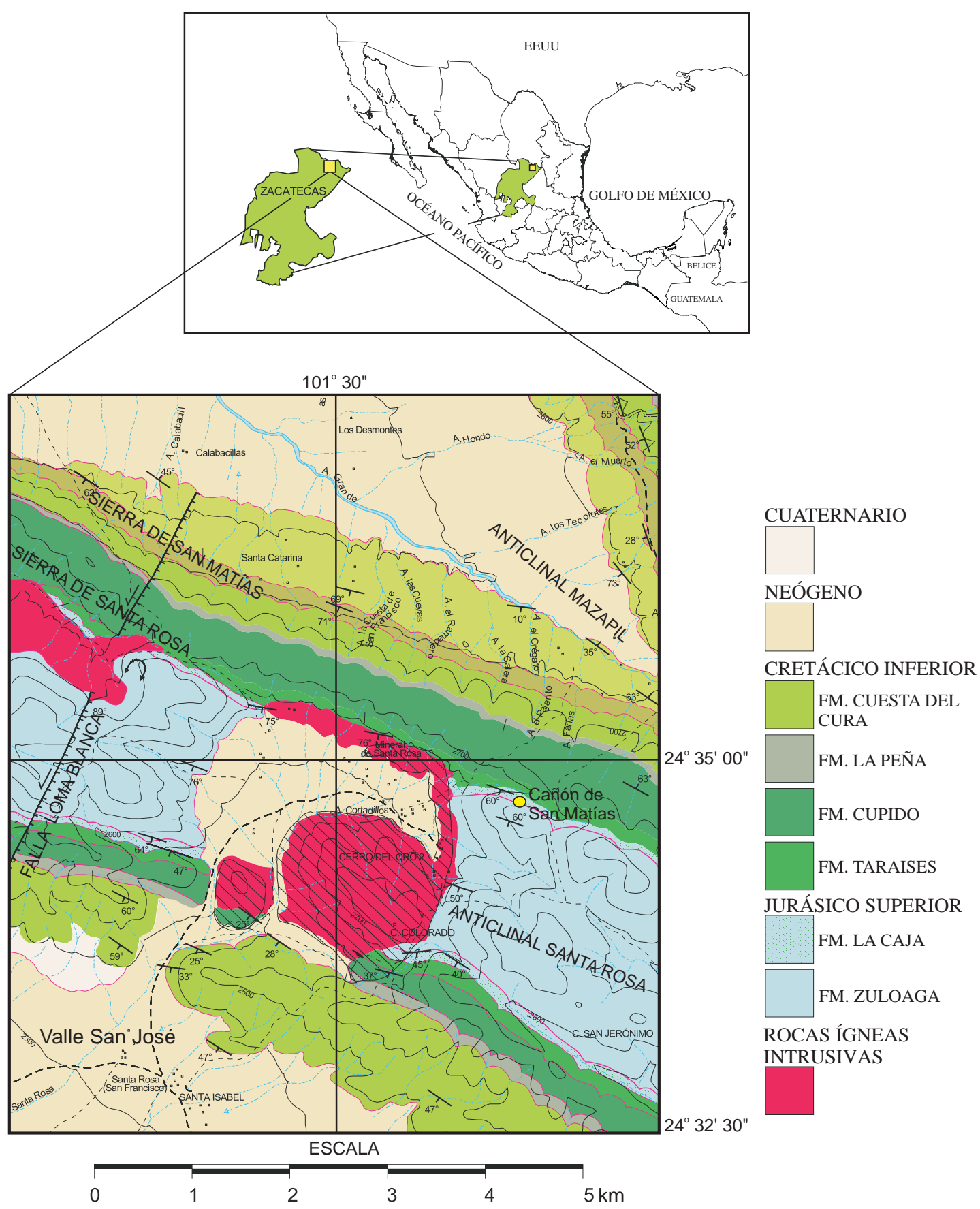

Figura 1 Mapa de localización geográfica (recuadro amarillo) y mapa geológico de la zona de estudio con la ubicación de la sección analizada en el perfil Cañón de San Matías - MZ-3 (círculo amarillo). Extraído de la Carta Geológico-Minera Concepción del Oro, ZacatecasCoahuila, G14-C62, escala 1: 50000 y modificado por Villaseñor et al., 2015. 
El contacto entre las formaciones La Caja y la subyacente Zuloaga representa localmente una paraconformidad (Sierra Santa Rosa, Zac., observaciones inéditas de los coautores $\mathrm{FO}$ y ABV) o una disconformidad (Sierra de Catorce, S.L.P., Olóriz et al., 1997, 1999; Sierra El Jabalí, Coah., Velasco-Segura, 2005; Sierra Santa Rosa, Zac., Villaseñor et al., 2015; Pto. Piñones, Coah., observaciones inéditas de $\mathrm{FO}$ y $\mathrm{ABV}$ ). En ambos casos el contacto incluye una laguna estratigráfica que abarca el Oxfordiano terminal y Kimmeridgiano basal, y se relaciona con la inundación del sistema de plataforma del Grupo Zuloaga y equivalentes en la periferia norte de la Cuenca del Golfo de México (Olóriz et al., 2003b; Villaseñor et al., 2012; y referencias incluidas), o bien es intra-Kimmerid giano basal de acuerdo con la reciente reinterpretación del límite Oxfordiano-Kimmeridgiano (Wierzbowski et al., 2016). El contacto superior del Grupo La Casita (formaciones La Casita-La Caja) con la Formación Taraises es paraconforme, aunque aún no es posible precisar sobre la posibilidad de disconformidades y la continuidad o discontinuidad del registro microestratigráfico a nivel local (Olóriz et al., 2003b). La edad de este contacto ha sido interpretada a diversos niveles del Berriasiano (Adatte et al., 1991, 1996; González-Arreola et al., 1992; Olóriz et al., 2003b; y referencias incluidas) frente a interpretaciones anteriores que lo situaban en el Tithoniano Superior (revisión en González-Arreola et al., 1992; Olóriz et al., 2003b y referencias incluidas). El relevo de sucesiones del Grupo La Casita (formaciones La Casita y La Caja) por sedimentos más carbonatados ha sido relacionado con un pulso de reorganización en la cuenca del Golfo de México y mejora de las conexiones oceánicas (Adatte et al., 1996; Olóriz et al., 2003b; Cobiella-Reguera y Olóriz, 2009). Intercalados entre dos intervalos carbonatados de significación claramente diferenciada, los materiales del Grupo La Casita representan una secuencia tectono-eustática de segundo orden (TES II/III en Olóriz et al., 2003b) que evidencia una fase en la evolución geológica de la Cuenca del Golfo de México.
Longoria (1984) expuso la variación en las interpretaciones sobre la profundidad de depósito para varias formaciones jurásicas en México, entre ellas la Formación La Caja. Para Goldhammer (1999, p. 25), la porción Kimmeridgiana de la Formación La Caja representaría la parte profunda de la rampa de la Formación Olvido, y el intervalo del Tithoniano al Berriasiano medio el equivalente de la Formación La Casita en la cuenca. De la Mora et al., (1999a, 1999b, 2000) interpretaron las condiciones eco-sedimentarias para la Formación La Caja en el perfil MZ-3 en el Cañón de San Matías, Zacatecas. A partir del análisis sedimentológico y de asociaciones de macrobentos, identificaron depósitos de grano fino en plataforma media a externa de baja energía, con niveles de oxigenación disaeróbica/poikiloaeróbica en los fondos, alto nivel de nutrientes, episodios de estrés ecológico y de mayor oxigenación, influencia de frentes de tormentas distantes con erosión incipiente o menor, efectos de aventamiento y retrabajamiento limitados, y producción de acumulaciones parautóctonas a manera de pavimentos con promediados temporales intra-habitat. En términos paleoambientales de ámbito regional, Olóriz et al. (2000) interpretaron ambientes neríticos de baja energía mostrando un gradiente deposicional N-S de depósitos siliclásticos (aquí Formación La Casita) a carbonatados (aquí Formación La Caja), profundidades de decenas de metros para intervalos con bivalvos y ammonites dominantes, limitaciones paleoambientales (ecológicas) como posibles factores incidentes en la alteración local de rangos bioestatigráficos, inundaciones episódicas que mejorarían las limitadas conexiones con masas de agua de mar abierto, e inestabilidad de fondos relacionada con actividad tectónica.

Olóriz et al. (2003b) interpretaron el Grupo La Casita como resultante del relevo de un sistema de plataforma carbonatada (Grupo Zuloaga) por incremento de aportes siliciclásticos (Formación La Casita en posición proximal y Formación La Caja distal) relacionados con la reactivación tectónica regional y cambios en la subsidencia y fluctuaciones en el nivel relativo del mar. 
Pessagno y Martin (2003) interpretaron una evolución paleobatimétrica comparable para todos los remanentes corticales dispersos de su terreno San Pedro del Gallo, con profundidades neríticas de plataforma interna durante el intervalo Calloviano-Oxfordiano temprano, de plataforma externa durante el Oxfordiano tardío, y batiales-abisales por encima de la ACD desde el Kimmeridgiano temprano hasta el final del Cretácico debido a un enfondamiento brusco (abisal superior; Pessagno y Martin, 2003, fig. 4). El contexto de evolución paleoambiental quedaría ligado a desplazamientos corticales relacionados con el denominado Walper Megashear, incluyendo desplazamientos desde latitudes $c a .40^{\circ} \mathrm{N}$ durante el Oxfordiano a nor-tethysianas $\left(>22^{\circ} \mathrm{N}\right.$ a $\left.<30^{\circ} \mathrm{N}\right)$ en el Cretácico temprano. En dicho contexto se depositaron la Caliza Zuloaga (profundidades menores a $50 \mathrm{~m}$ ) y la Formación La Caja, lo cual se muestra con base a las asociaciones de radiolarios y macrofósiles, interpretando apariciones bruscas de los primeros como indicadoras de cambios paleobatimétricos relevantes (p.ej., de plataforma interna a externa), asumiendo condiciones de barro de radiolarios radiolarian ooze- para horizontes silíceos de la Formación La Caja. Según estos autores (p. 54, 62), el depósito de la Formación La Caja en el área de Mazapil, durante el Jurásico tardío y el Cretácico temprano, ocurrió en profundidades abisales superiores o quizá en profundidades batiales inferiores, por arriba del nivel de compensación de la aragonita.

En el área de estudio, el intervalo estratigráfico en el que se identificaron las concentraciones fosilíferas analizadas ha sido asignado al Kimmeridgiano superior por Burckhardt (1906b); los horizontes más carbonatados han sido correlacionados con la Zona Eudoxus del estándar biocronoestratigráfico europeo por Villaseñor (1991) y Villaseñor et al., (2000, 2012), con diferenciación de una nueva sub biozona en este trabajo (consultar sección 3.2).

Sección estudiada. El perfil analizado se denomina Cañón de San Matías (MZ-3), y se localiza al sureste de la Ciudad de Concepción del Oro, en el Municipio de Mazapil. Aflora en la Sierra de Santa Rosa, que pertenece a la subprovincia de "Sierras Transversales", se ubica próximo al poblado de Santa Rosa, cercano a la antigua mina de Mineral de Santa Rosa; las coordenadas geográficas son 2434'51.7" N y 101²9'4.0" W (Figura 1). La selección del perfil Cañón de San Matías (Figura 2) se debe a que es un afloramiento de referencia para diversos autores, cuyo estudio data del siglo pasado. Burckhardt (1906a y b) fue el primero en estudiarlo, enfocando su investigación al conocimiento estratigráfico y bioestratigráfico del Jurásico Superior de la región de Mazapil, Zacatecas. Su principal contribución fue la de dar a conocer la fauna de ammonites, realizando un estudio detallado de su sistemática y bioestratigrafía. La publicación de Burckhardt (1906b) hizo de este perfil un referente regional para el Jurásico Superior de México.

Imlay (1939) sucedió a Burckhardt (1906b, 1930) en el estudio de secciones estratigráficas en México, entre ellas la del Cañón de San Matías, dando formalidad a la denominación de las sucesiones litoestratigráficas mencionadas por Burckhardt (1906a y b, 1930), en ocasiones ampliando la información paleontológica y en otras concretando algunos de los alcances bioestratigráficos de la fauna colectada.

Villaseñor (1991) analizó cuatro perfiles, incluido el de Cañón de San Matías que denominó Perfil MZ-3; en este estudio precisó y complementó la sistemática y la bioestratigrafía de la fauna de ammonites del Kimmeridgiano-Berriasiano, resaltando el carácter discontinuo de los intervalos bioestratigráficos reconocidos, además de esbozar una interpretación paleoambiental en términos de plataforma con profundidades entre 30 y $100 \mathrm{~m}$. Lara-Morales (1994) incluyó en su estudio la fauna colectada por Villaseñor (1991) y realizó nuevas colectas en el Perfil MZ-3. Su investigación se basó en detallar la distribución estratigráfica del género Idoceras Burckhardt, 1906, y en la re-evaluación sistemática a nivel de especie. Corroboró la biozonación propuesta por Villaseñor (1991).

De la Mora (1998) y De la Mora et al. (1999a, 
A

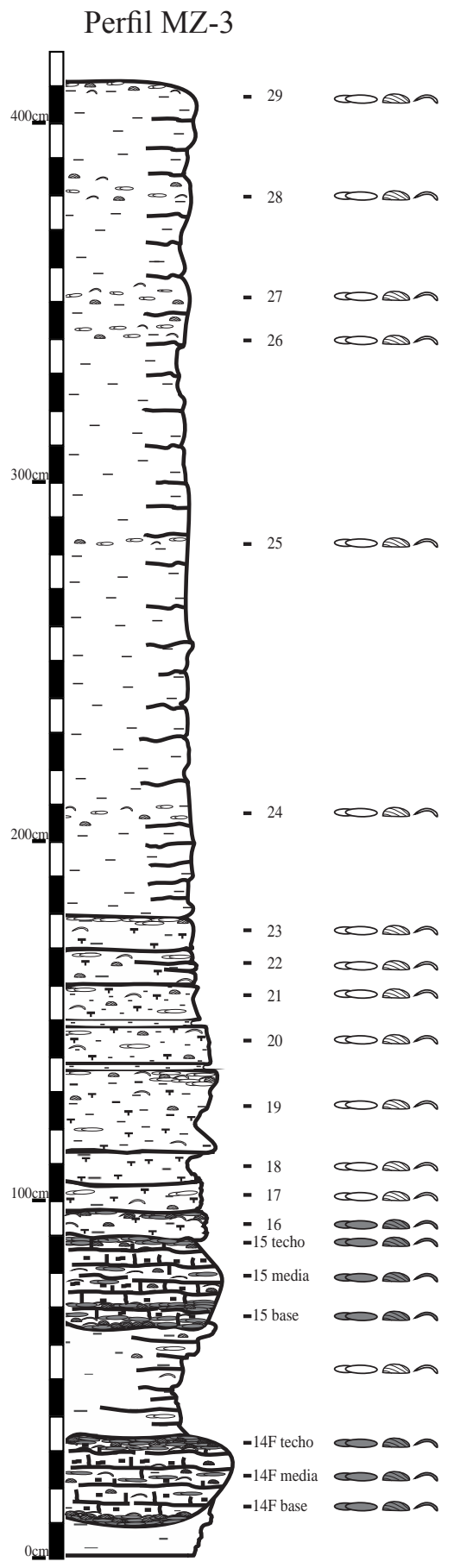

LEYENDA

Litología

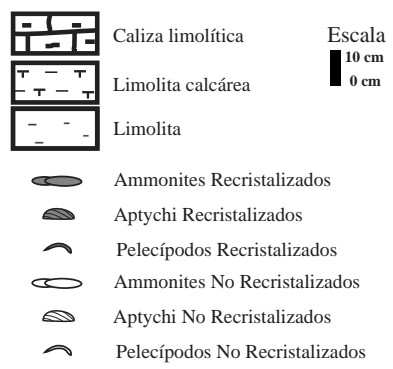

B

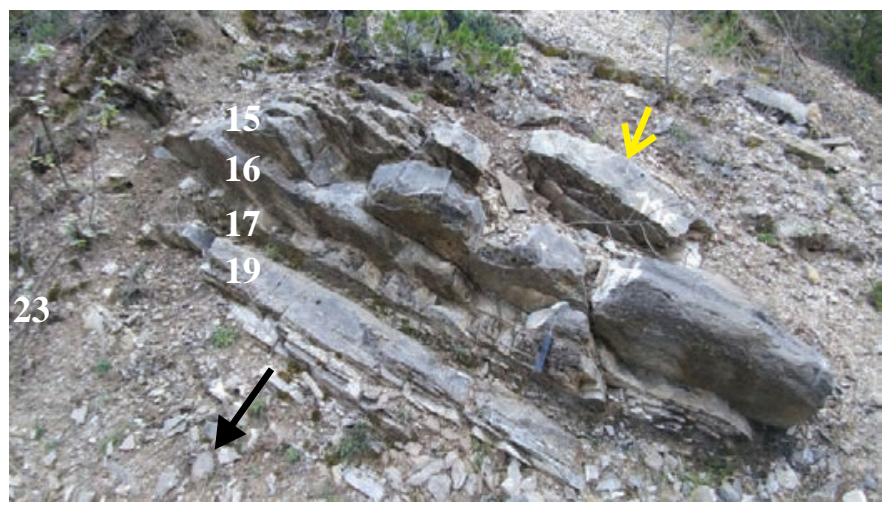

C

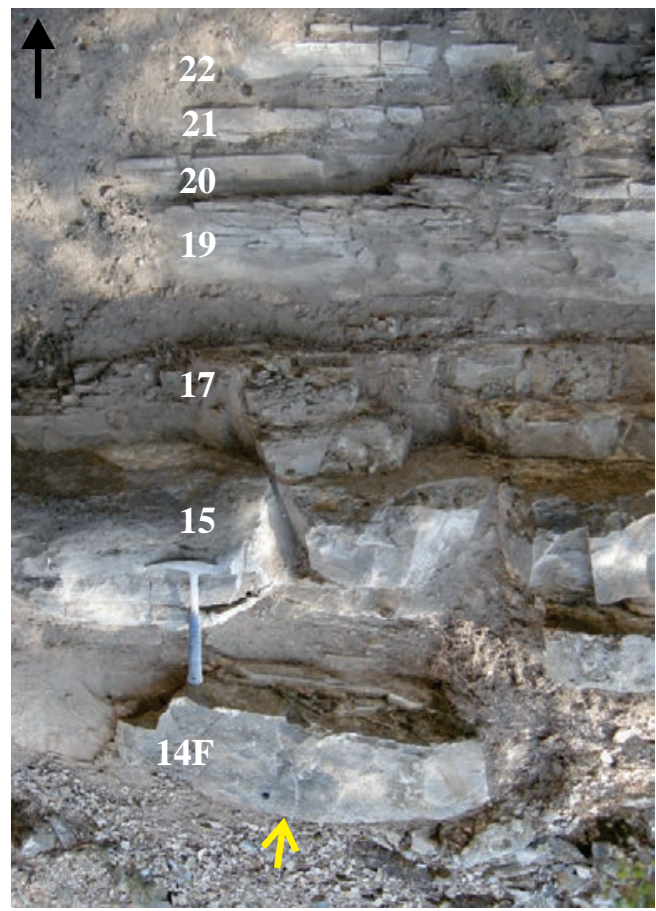

Figura 2 Perfil Cañón de San Matías (MZ-3). (A) Columna litológica (espesor $410 \mathrm{~cm}$ ) con acumulaciones fosilíferas restringidas a los estratos basales, 14F y 15. (B) Vista de afloramiento con sucesión invertida que muestra la geometría irregular, en los depósitos carbonatados y tabular en las limolitas rosadas-grisáceas (estratos 17 al 23). (C) Imagen invertida que muestra $170 \mathrm{~cm}$ correspondientes al intervalo $14 \mathrm{~F}$ al 22, para apreciar la geometría de las unidades de depósito destacando la base cóncava del estrato $14 \mathrm{~F}$ (¿impronta diagenética? flecha amarilla). Flecha en negro para indicar polaridad estratigráfica. Martillo como escala (32 cm). 
1999b, 2000) estudiaron la fauna de bivalvos del perfil Cañón de San Matías (MZ-3), con enfoques sistemáticos, taxonómicos, bioestratigráficos y tafonómicos (detalles en la sección 1.2.1.).

Olóriz et al. (1998, 2000), al analizar la fauna de Procraspedites y de microconchas de Hybonoticeras de México, incluyeron ejemplares colectados en el Perfil Cañón de San Matías (MZ-3) y con ello profundizaron en detalles bioestratigráficos e interpretaciones paleobiogeográficas (las interpretaciones paleoambientales se han comentado brevemente en la sección 1.2.1.).

Pessagno y Martin (2003) realizaron una interpretación tectonoestratigráfica derivada de diversas investigaciones que abordan aspectos de bioestratigrafía, cronoestratigrafía, paleobatimetría, paleobiogeografía y litoestratigrafía, en relación de su propuesta de fases para el origen y evolución de la apertura del Golfo de México. Realizaron observaciones en el Cañón de San Matías, cuya sucesión la interpretaron como perteneciente a Mazapil "remnant", resto, vestigio o remanente del terreno tectonoestratigráfico San Pedro del Gallo. Analizaron las microfacies y la asociación de micro y macrofósiles para concluir que los depósitos de la Formación La Caja (Jurásico tardío a Berriasiano temprano) corresponden a un ambiente de profundidades abisales a batiales sobre la ACD, debido a la presencia de restos de ammonites. Dicho contexto ambiental implicaría un cambio brusco respecto a las condiciones relacionadas con el depósito de la Caliza Zuloaga, en la que interpretaron un evento del Oxfordiano tardío que forzaría el cambio desde condiciones de plataforma interna $(<50 \mathrm{~m})$ a externa $(c a .200$ m). Además, para el "remanente" Mazapil asumieron un desplazamiento $>8^{\circ}$ desde latitudes sub-boreales $\left(>30^{\circ} \mathrm{N}\right)$ a tethysianas septentrionales (entre $22^{\circ}$ y $30^{\circ} \mathrm{N}$ ) durante el Kimmeridgiano temprano al Tithoniano tardío. La interpretación de estos autores ofrece un escenario de evolución paleoambiental claramente diferenciada respecto a las interpretaciones anteriores e incluye desplazamientos corticales y temporizaciones sobre los que aún no existe consenso en el contexto de las interpretaciones recientes sobre el origen y evolución del Golfo de México (p.ej., Martini y Ortega-Gutiérrez, 2016).

De acuerdo con los antecedentes comentados, el perfil MZ-3 se considera un perfil clásico, merecedor de estudios detallados. La sección en el Cañón de San Matías (MZ-3) mide en su totalidad, aproximadamente $110 \mathrm{~m}$ (Villaseñor, 1991) y el espesor correspondiente a los depósitos muestreados para este trabajo es de $410 \mathrm{~cm}$ (Figura 2A). Se trata de estratos de caliza limolítica con espesores mayores a $15 \mathrm{~cm}(10 \%)$ y que se localizan en la parte inferior de la sucesión estudiada. Los estratos que sobreyacen son limolitas poco calcáreas, con espesores de $10-15 \mathrm{~cm}(20 \%)$ que pueden mostrar acuñamiento lateral. La litología que se presenta en los estratos superiores es de limolita con geometría tabular y espesor variado, con rangos de 5 - $10 \mathrm{~cm}(40 \%)$ y menores de $5 \mathrm{~cm}(30 \%$ ) (Figura 2B y 2C). En el afloramiento de Cañón de San Matías (MZ-3) se estudian los niveles con concentraciones de fósiles del Kimmeridgiano Superior dado que hasta la fecha no habían sido objeto de análisis detallados, ni en términos tafonómicos ni de condiciones de depósito.

\section{Material y métodos}

El objetivo de inferir los procesos generadores de las concentraciones fosilíferas implica el estudio de los horizontes fosilíferos (acumulaciones) en su contexto estratigráfico. La relación estrecha entre las litofacies y el patrón o tipo de estratificación reconocido, así como la necesidad de simplificar la identificación de las muestras sin pérdida de información, han aconsejado optar por una diferenciación terminológica ad hoc, en la que términos comunes como "nivel", "estrato" y "horizonte" no se utilizan como sinónimos en cuanto a referentes estratigráficos. El término "nivel" solo se ha utilizado para un intervalo estratigráfico de litofacies constante y espesor variable (limolitas gris-rosadas), situado por encima de los depósitos fosilíferos más carbonatados, conformado por unidades elemen- 
tales de depósito de escaso espesor (estratificación muy fina a laminar) y agrupadas irregularmente en cuerpos sedimentarios compuestos, tabulares y de espesor variable; así el término "nivel" permite referir a esos cuerpos sedimentarios compuestos y tabulares, a veces poco definidos en el afloramiento. El término "estrato" se restringe a cuerpos rocosos carbonatados con mayor o menor diferenciación interna, fácilmente reconocibles en el afloramiento y, por tanto, se consideran niveles guía. El término "horizonte" se refiere a cada una de las subdivisiones, fosilíferas o no, identificadas en un "estrato", tal como este término ha sido considerado, o bien a una unidad elemental de depósito en el interior del "nivel" limolítico. La diferenciación terminológica propuesta responde a la percepción intuitiva de campo en la que "nivel" resulta una referencia relativamente "subjetiva" en cuanto a la delimitación del cuerpo sedimentario (intervalo limolítico relativamente potente en el caso estudiado), "estrato" es la unidad macroscópica estándar reconocible en estratigrafía de campo (depósitos más carbonatados claramente diferenciables en el caso estudiado), y "horizonte" será la referencia estratigráfica más precisa, identificando una unidad elemental de depósito en cualquier tipo de litofacies. Definido en un contexto sedimentológico-estratigráfico, el término "horizonte" no es sinónimo de biohorizonte $\mathrm{u}$ horizonte bioestratigráfico.

Se ha realizado un muestreo a nivel centimétrico con observaciones estratigráficas, sedimentológicas, tafonómicas, e identificaciones taxonómicas y bioestratigráficas.

Entre las observaciones sedimentológicas-estratigráficas se han tenido en cuenta aspectos como litofacies y cuerpos sedimentarios encajantes, geometría del depósito fosilífero, tipo de contactos de las unidades de depósito (abruptos, gradacionales, erosivos, etc.), y litología y fábrica u organización macro- y microscópica del depósito, independientemente del contenido fosilífero. Todo ello se ha complementado con observaciones macroscópicas realizadas en superficies de corte orientadas en bloques de roca carbonatada y también con el estudio petrográfico de láminas delgadas. Para el estudio de las microfacies se analizaron 34 láminas delgadas, determinándose la abundancia y clasificación de los componentes por campo de observación; para estimar la abundancia de granos y matriz se utilizaron cartas de estimación visual por porcentajes. Las observaciones tafonómicas, y la composición taxonómica, se consideraron para inferir los procesos bioestratinómicos que pudieran dar información acerca de los agentes involucrados en el tipo de concentración (Kidwell et al., 1986; Kidwell, 1991; Fürsich y Oschmann, 1993) y de las condiciones de depósito. En campo se tomaron datos de orientación de los restos y grado de empaquetamiento, que se complementaron con el análisis de las superficies de corte obtenidas en los bloques de roca suficientemente carbonatada (estratos) y con concentraciones fosilíferas, con la finalidad de conocer su acomodo tridimensional. Para el estudio tafonómico se analizaron un total de 1175 muestras. De cada estrato y horizonte muestreados se analizaron las siguientes variables.

1. número de ejemplares completos versus fragmentos y se calculó el índice de fragmentación (sensu Olóriz et al., 2002b);

$\mathrm{IF}=[(\mathrm{nGFA} \times 100)+(\mathrm{nGFM} \times 50)+(\mathrm{nGFB} \times 1)] / \mathrm{N}$

2. distribución de tamaños de los ejemplares de acuerdo a cuatro rangos o clases de tamaño (<30 mm; $30-60 \mathrm{~mm} ;>60-90 \mathrm{~mm} \mathrm{y}>$ $90 \mathrm{~mm}$ );

3. orientación de los restos fosilíferos macroscópicos (paralela, oblicua, verticalizada) respecto a la dirección y plano definido por la estratificación, y su grado de empaquetamiento;

4. la articulación/desarticulación en pelecípodos y la posición de sus valvas (cóncavas o convexas); análogo tratamiento se aplicó a los aptychi.

5. tipo de conservación (impresión o huella, molde interno, y relleno recristalizado) con indicación, en su caso, del índice de "corrasion" (sensu Olóriz et al., 2002b).

$\mathrm{IC}=[(\mathrm{n}$ GGA $\times 100)+(\mathrm{nGCM} \times 50)+(\mathrm{nGCB} \times 1)] / \mathrm{N}$ Hay que resaltar que para caracterizar el empaquetamiento se reconocieron diferentes rangos de concentración y tipo de preservación, asig- 
nándoles las siguientes siglas complementarias: ER (ejemplares recristalizados) y EL (ejemplares limolíticos). Se reconocieron seis grados de empaquetamiento (0 a 4 y un intermedio, 0.5), principalmente para los ejemplares recristalizados, ya que son los que mejor evidencian las concentraciones fosilíferas, puesto que los moldes internos dominantes en las limolitas revelan una compactación considerable. Estos tipos de empaquetamiento se definieron de la siguiente manera:

i. ER0 - EL0.- sin macrofósiles observables, (Figura $3 \mathrm{~A})$.

ii. ER0.5 - EL0.5 refieren a empaquetamiento "flotado" (restos aislados en la matriz, a veces mostrando alineaciones discontinuas; Figura $3 \mathrm{~B})$.

iii. ER1 - EL1.- "flotado" laminar (láminas individualizadas, con espesor $0.3 \mathrm{~cm}$ en la matriz; Figura $3 \mathrm{C}$ ).

iv. EL2 - ER2.- "flotado" laminar con enclaves de orientación caótica" (organización de restos puntualmente caótica; Figura 3D).

v. EL3 - ER3.- denso laminar (restos en contacto, $1.5 \mathrm{~cm}$ de espesor; Figura 3E).

vi. EL4 - ER4.- denso laminar con disposición caótica (espesor de $4 \mathrm{~cm}$; Figura 3F).

Respecto al estudio de microfacies se utilizó la clasificación de Wright (1992); para detalles ver Tabla 1.

La información de campo y gabinete se integró en bases de datos en Excel, utilizadas para establecer los grados tafonómicos y apoyar la interpretación tafonómica, de microfacies, del medio de depósito, y paleoambiental.

\section{Resultados}

\subsection{HORIZONTES FOSILÍFERAS \\ GON AGUMULAGIONES}

\subsubsection{PERFIL CAÑÓN DE SAN MATÍAS (MZ-3)}

La sucesión estudiada del perfil MZ-3 representa una subsección con espesor total de $410 \mathrm{~cm}$. Los estratos que presentan las concentraciones fosilífe- ras se restringen a los $100 \mathrm{~cm}$ de la parte inferior de la sucesión (Figura 4A).

En la base se presentan dos estratos de composición calcáreo-limolítica. El inferior, 14F, tiene un espesor de $31 \mathrm{~cm}$ y presenta base cóncava y techo aplanado, concordante (Figura 4G). Observaciones macroscópicas permiten reconocer horizontes de acumulación de fósiles diferenciados como $14 \mathrm{~F}$ base, $14 \mathrm{~F}$ media y $14 \mathrm{~F}$ techo (Figura $4 \mathrm{~A}$ ). En el horizonte $14 \mathrm{~F}$ base se presenta gran cantidad de fósiles y la concentración disminuye hacia la parte media (horizonte $14 \mathrm{~F}$ media). En la parte superior se registra un nuevo horizonte con gran acumulación de restos con evidencias de imbricación (horizonte $14 \mathrm{~F}$ techo; Figura 5A). El techo de este horizonte es la superficie de estratificación en la que no se reconoce orientación preferencial de restos que implique efecto de flujo direccional. Suprayaciendo al estrato 14 hay un interlecho de composición limolítica con espesor de $33 \mathrm{~cm}$ en donde no se identificaron restos fósiles. El segundo estrato con concentración fosilífera, estrato 15, presenta un espesor máximo de $27 \mathrm{~cm}$, con superficies de base y techo irregulares (Figura 4B). La subdivisión en horizontes 15 base, 15 media y 15 techo, responde a la diferenciación interna de acumulaciones de restos fósiles (Figura 4B). En general en los estratos de composición más calcárea (14F y 15) los restos fósiles recristalizados con frecuencia muestran compresión ("aplastamiento") parcial.

La parte media de la subsección estudiada está representada por $90 \mathrm{~cm}$ de limolitas menos calcáreas, con estratificación fina hasta $10 \mathrm{~cm}$, en unidades elementales de depósito de espesor milimétrico que se agrupan en cuerpos sedimentarios compuestos de espesor variable entre 9 y $25.5 \mathrm{~cm}$, manteniendo el aspecto tabular típico para este tramo de la sucesión (Figuras 2A, 2B, 2C, 5E y $5 \mathrm{~F})$.

La parte media y superior de la sucesión estudiada, con un espesor total $230 \mathrm{~cm}$, está empobrecida en restos fósiles y compuesta principalmente por limolitas con estratificación tabular fina, 5 a 10 $\mathrm{cm}$ (Figuras 5E y 5F). Sólo se han reconocido im- 
Tipos de empaquetamiento

ERO / ELO-Sin M acrofósiles observables ER1/EL1 - "Flotado" laminar ER0.5 / EL0.5- "Flotado"

ER2/EL2 - "Flotado" Iaminar con

enclaves de orientación caótica
ER3/EL3 - Denso laminar

ER4/EL4 - Denso laminar con

enclaves de orientación caótica
ERO

\section{A}

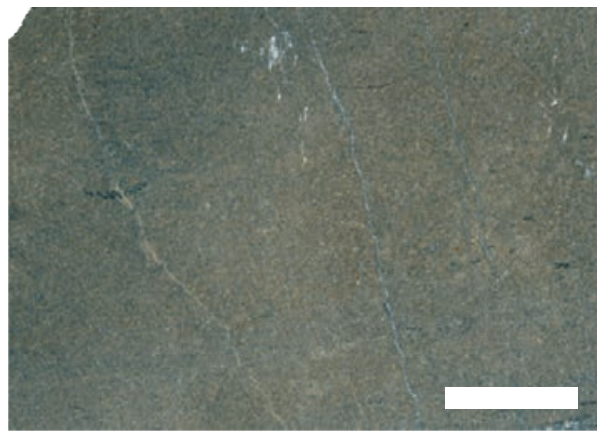

ER1

C

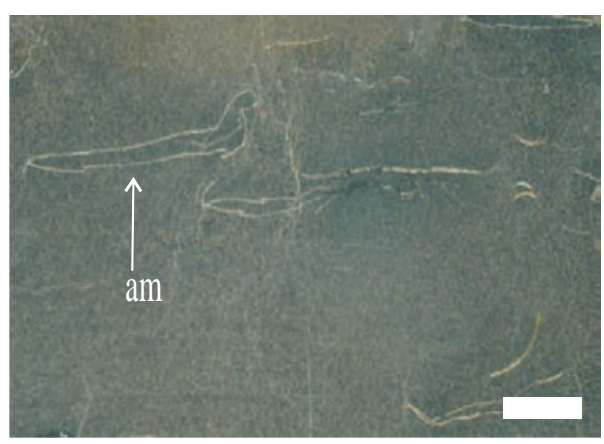

ER3

E

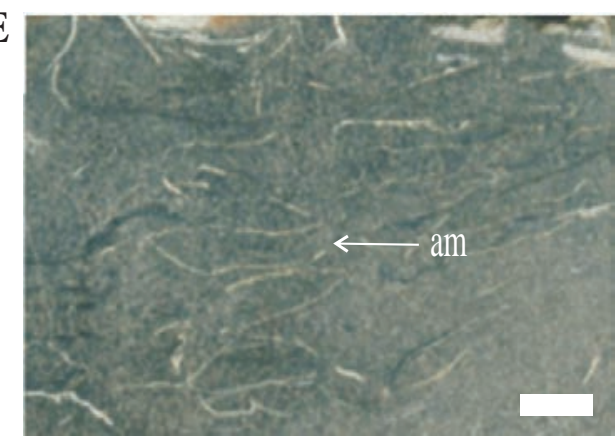

ER 0.5

B

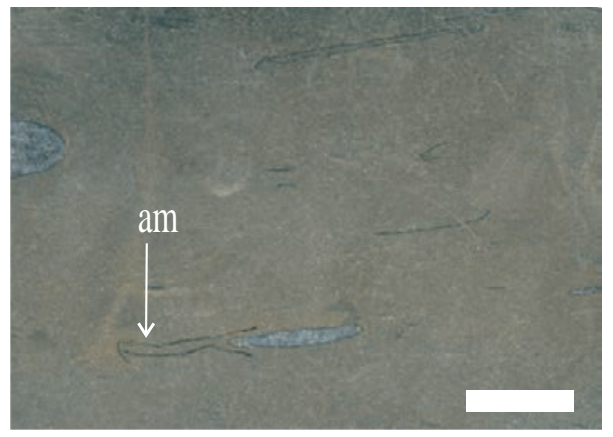

ER2

D

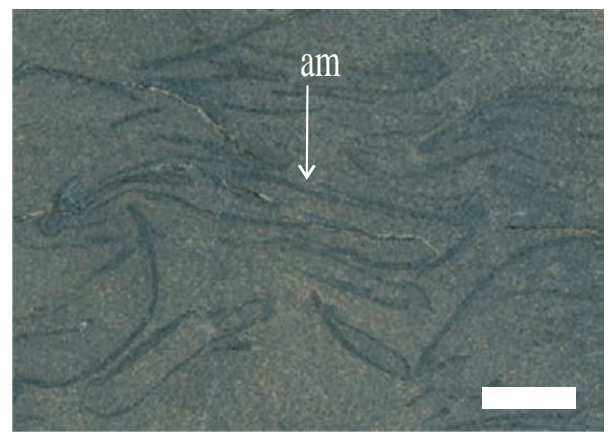

ER 4

$\mathrm{F}$

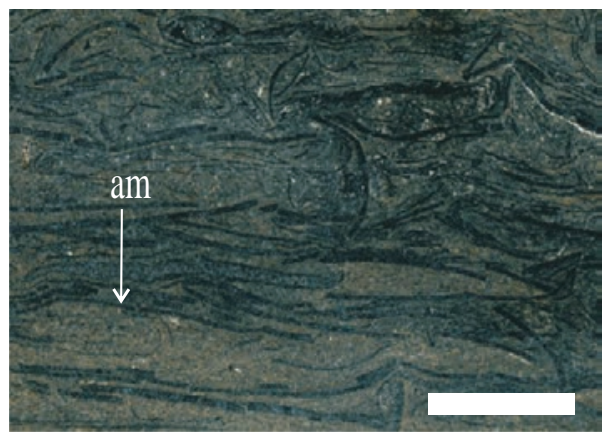

Figura 3 Tipos de empaquetamiento identificados en el Perfil Cañón de San Matías (MZ-3), de acuerdo con la densidad de la concentración y el tipo de preservación de los restos en muestras del estrato 16 (A) y horizontes 14F media (B), 15 techo (C, E) y 14F base (D, F). Se muestran seis tipos de empaquetamiento -0 a 4 y un intermedio, 0.5 . Nótense bioclastos disueltos reconocibles por el relleno insoluble (tonalidades claras en $\mathrm{C}$ y E). Flechas blancas para indicar ammonites (am). Barra $1 \mathrm{~cm}$. Las imágenes fueron editadas digitalmente para resaltar los rasgos de la fábrica y empaquetamiento. Para detalles véase el texto. 
Tabla 1. Abundancia de bioclastos (representada en porcentajes) reconocidos en las microfacies de los horizontes y estratos del perfil Cañón de San Matías (MZ-3). Asterisco (*) para un solo ejemplar.

\begin{tabular}{|c|c|c|c|}
\hline Microfacies & Horizonte/Estrato & Bioclasto & $\begin{array}{c}\text { Abundancia bioclastos } \\
(\%)\end{array}$ \\
\hline \multirow{8}{*}{$\begin{array}{l}\text { Floatstone-wackestone de } \\
\text { bioclastos con parches locales de } \\
\text { packstone }\end{array}$} & \multirow{8}{*}{$14 \mathrm{~F}$ base } & Ammonites & 2 \\
\hline & & Ammonitellas & 1 \\
\hline & & Aptychi & 5 \\
\hline & & Bivalvos articulados & 10 \\
\hline & & Braquiópodos & 3 \\
\hline & & Calciesferas & 1 \\
\hline & & Radiolarios & 1 \\
\hline & & Fragmentos de molusco (bivalvos) & 7 \\
\hline \multirow{46}{*}{$\begin{array}{l}\text { Floatstone-wackestone de } \\
\text { radiolarios }\end{array}$} & \multirow{5}{*}{$14 \mathrm{~F}$ media } & Calciesferas & 4 \\
\hline & & Radiolarios & 10 \\
\hline & & Fragmentos de molusco (bivalvos) & 5 \\
\hline & & Foraminiferos? & 1 \\
\hline & & Litoclastos? & 1 \\
\hline & \multirow{4}{*}{14 techo } & Bivalvos articulados & 10 \\
\hline & & Calciesferas & 7 \\
\hline & & Radiolarios & 10 \\
\hline & & Fragmentos de molusco (bivalvos y no determinados) & 5 \\
\hline & \multirow{4}{*}{15 base } & Bivalvos articulados & 5 \\
\hline & & Calciesferas & 5 \\
\hline & & Radiolarios & 15 \\
\hline & & Fragmentos de molusco (no determinados) & 5 \\
\hline & \multirow{4}{*}{15 techo } & Aptychi & 5 \\
\hline & & Bivalvos articulados & 10 \\
\hline & & Radiolarios & 10 \\
\hline & & Fragmentos de molusco (no determinados) & 5 \\
\hline & \multirow{4}{*}{16} & Aptychi & 5 \\
\hline & & Calciesferas & 5 \\
\hline & & Radiolarios & 15 \\
\hline & & Fragmentos de molusco (no determinados) & 5 \\
\hline & \multirow{6}{*}{17} & Aptychi & 4 \\
\hline & & Bivalvos articulados & 8 \\
\hline & & Calciesferas & 5 \\
\hline & & Radiolarios & 10 \\
\hline & & Fragmentos de molusco (no determinados) & 3 \\
\hline & & Saccoccoma & $*$ \\
\hline & \multirow{4}{*}{18} & Aptychi & 5 \\
\hline & & Bivalvos articulados & 10 \\
\hline & & Radiolarios & 10 \\
\hline & & Fragmentos de molusco (bivalvos y no determinados) & 5 \\
\hline & \multirow{6}{*}{19} & Aptychi & 3 \\
\hline & & Bivalvos articulados & 8 \\
\hline & & Calciesferas & 5 \\
\hline & & Radiolarios & 10 \\
\hline & & Litoclastos? & 1 \\
\hline & & Fragmentos de molusco (no determinados) & 3 \\
\hline & \multirow{5}{*}{20} & Bivalvos articulados & 8 \\
\hline & & Calciesferas & 3 \\
\hline & & Radiolarios & 15 \\
\hline & & Dinoflagelados? & 1 \\
\hline & & Fragmentos de molusco (no determinados) & 3 \\
\hline & \multirow{4}{*}{21} & Aptychi & 5 \\
\hline & & Bivalvos articulados & 10 \\
\hline & & Radiolarios & 10 \\
\hline & & Fragmentos de molusco (no determinados) & 5 \\
\hline
\end{tabular}


A

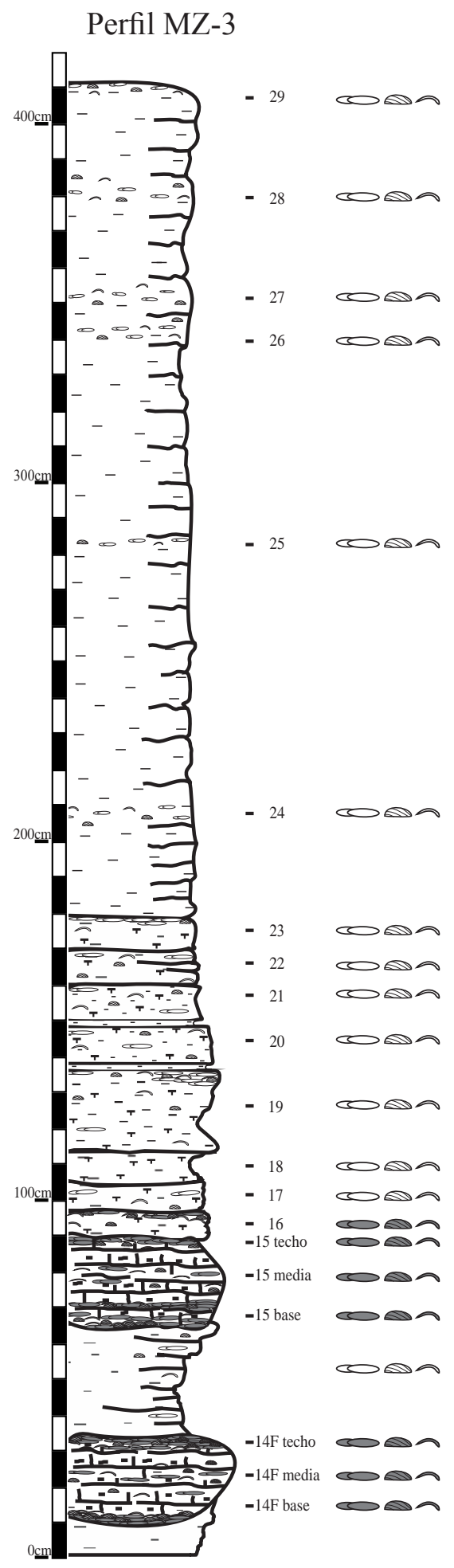

LEYENDA

Litología

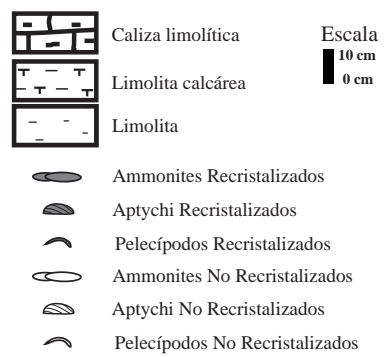

B

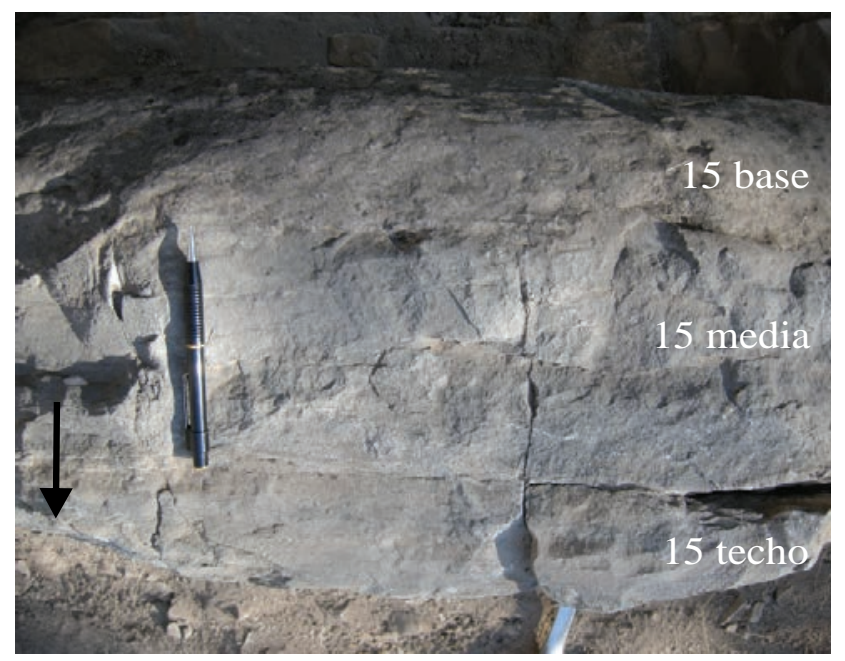

C

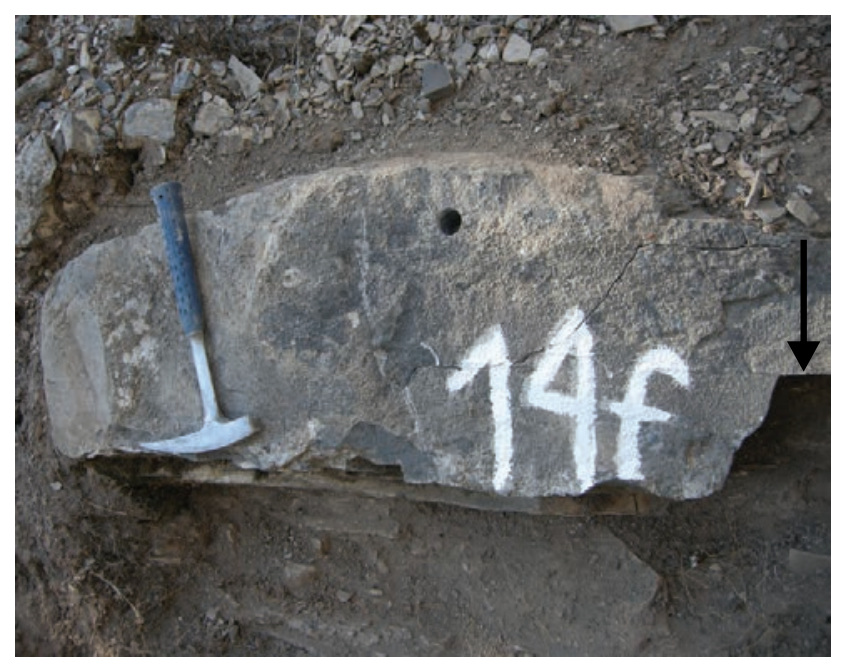

Figura 4 Geometría de estratos calcáreos y limolíticos en el Perfil Cañón de San Matías (MZ-3). (A) Columna litológica (espesor 410 cm). (B) Geometría irregular, concrecional, del estrato 15 (impronta diagenética sobre ligera depresión a base y convexidad a techo). (C) Base cóncava y techo aplanado en el nivel 14F, en posición invertida en el afloramiento. Flechas negras indican la polaridad estratigráfica (imágenes invertidas). Martillo $(32 \mathrm{~cm})$ y portaminas $(15 \mathrm{~cm})$ como escala. 
presiones de restos fósiles de ammonites, aptychi y bivalvos.

\subsubsection{TAFONOMÍA}

La caracterización tafonómica de los constituyentes de la asociación fósil en cada uno de los horizontes fosilíferos identificados aporta información valiosa para la interpretación de los procesos relacionados con el acumulo de las conchas.

Empaquetamiento. En general, el empaquetamiento en los horizontes identificados es más denso en la parte inferior de la sucesión estudiada. Las concentraciones se acentúan más hacia la base y techo de los estratos, en forma de horizontes con expresión superficial de pavimentos (Figuras 5B, 5D), sin descartar la posible discontinuidad lateral, no apreciable por limitaciones de afloramiento, o bien de capas en función de su espesor (respectivamente pavements, stringers y beds de Kidwell et al., 1986; Figuras 5A, 5C). En el plano correspondiente al espesor del cuerpo sedimentario de referencia, las acumulaciones de restos son discontinuas. Considerando los tipos de empaquetamiento propuestos, cuyos ejemplos se comentan en detalle más adelante, el primer estrato $(14 \mathrm{~F})$ muestra en su espesor variaciones en la densidad y tipo de empaquetamiento; en la base del estrato (horizonte 14F base, Figura 6B) se presentan $10 \mathrm{~cm}$ de empaquetamiento tipo ER4 (denso laminar con enclaves de orientación caótica); en la parte media (horizonte $14 \mathrm{~F}$ media de $15 \mathrm{~cm}$ de espesor, Figuras $6 \mathrm{~A}, 6 \mathrm{~B}$ ) el tipo de empaquetamiento cambia de ER0 en los $5 \mathrm{~cm}$ inferiores a ER0.5 en los $10 \mathrm{~cm}$ superiores con presencia de restos fósiles "flotados"; hacia techo (horizonte $14 \mathrm{~F}$ techo), el empaquetamiento se incrementa progresivamente, iniciando con un tipo ER1 ("flotado" laminar) con espesor de $3 \mathrm{~cm}$, ER2 ("flotado" laminar con enclaves de orientación caótica) con espesor de $3 \mathrm{~cm}$ y algunos parches con empaquetamiento tipo ER3 (contacto laminar; Figura 6C, en la que solo se muestra la parte media y alta del horizonte).

El paquete limolítico que suprayace al nivel 14F, presenta un espesor de $33 \mathrm{~cm}$ y se consideró como un interlecho donde los restos fosilíferos se presen- tan no recristalizados, como moldes internos comprimidos ("leaf preservation") y huellas ("imprints"), con empaquetamiento tipo EL0.5 (Figura 6A). En el estrato 15, con un espesor de $27 \mathrm{~cm}$ (Figura $6 \mathrm{~A})$, se presentan tres tipos de empaquetamiento: en el horizonte 15 base ( $8 \mathrm{~cm}$ de espesor) se registran restos recristalizados y empaquetamiento variable con la sucesión ER1 ("flotado" laminar), ER0.5 ("flotado"), ER1 ("flotado" laminar) y finalmente ER2 ("flotado" laminar con enclaves de orientación caótica) (Figura 6D); la parte media del estrato (horizonte 15 media) con un espesor de $14 \mathrm{~cm}$, muestra un cambio progresivo de empaquetamiento ER0 a ER0.5 ("flotado") (Figura 6E); la parte superior del estrato (horizonte 15 techo) con un espesor de $5 \mathrm{~cm}$ se ha caracterizado con empaquetamiento tipo ER0.5 ("flotado") que es relevado por tipo ER1 ("flotado" laminar, Figura $6 \mathrm{~F})$.

El estrato (16) con un espesor de $9 \mathrm{~cm}$ presenta la mayor densidad del empaquetamiento en la parte superior, se inicia con empaquetamiento tipo ER0.5 ("flotado") y posteriormente ER1 ("flotado" laminar, Figura 6G).

El resto de los estratos y niveles analizados (17 al 29), con un espesor total de $80 \mathrm{~cm}$, se caracterizan por presentar exclusivamente moldes internos limolíticos (EL) parcialmente comprimidos y empaquetamiento tipo EL0.5 ("flotado") dominante (Figura 6A).

Asociaciones faunísticas. Las asociaciones de macroinvertebrados (Figura 7) están constituidas por ammonites, aptychi, bivalvos y gasterópodos. Un total de 1175 restos analizados (especímenes parcialmente completos y fragmentos). De manera general los ammonites son los mejor representados $(53 \%)$, excluidos aptychi $(27 \%)$; bivalvos como componentes accesorios (18\%); y gasterópodos ocasionales $(2 \%)$. La abundancia en restos de ammonites es variable a lo largo de la sucesión estudiada; el primer registro se ubica en el horizonte $14 \mathrm{~F}$ base $(44 \%$ del total de la fauna registrada), mientras que en los niveles de la parte media (16 al 19) se incrementa hasta $77 \%$. En los 2 m superiores de la sucesión el porcentaje de ammonites 
A

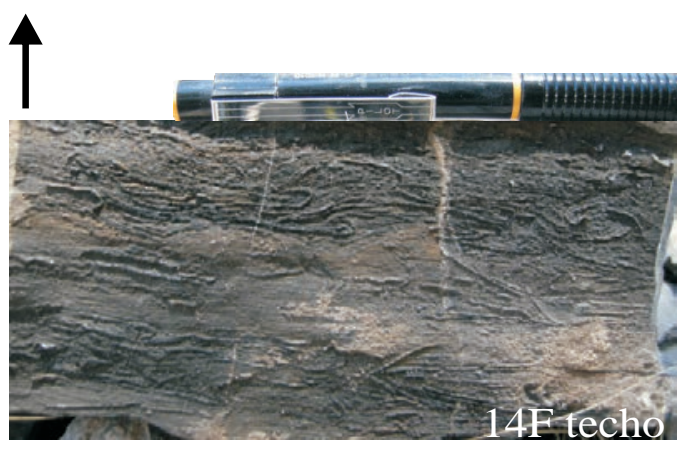

C

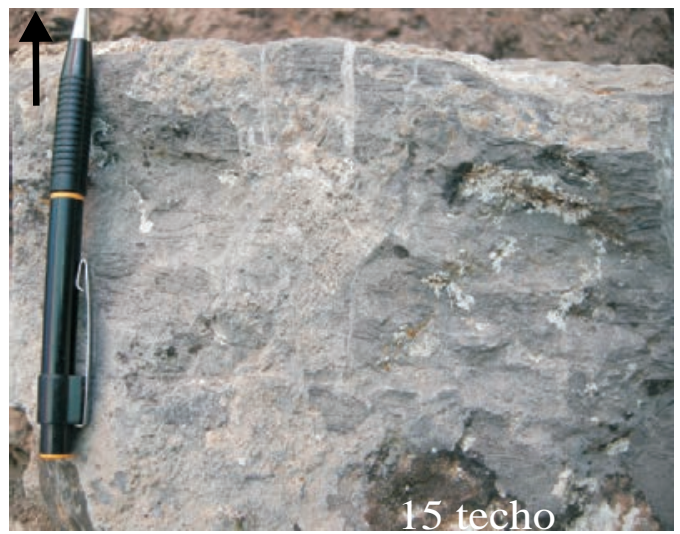

B

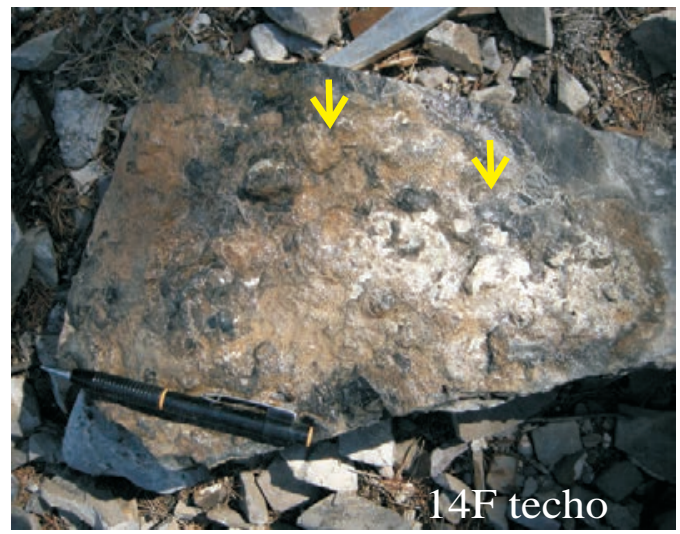

D

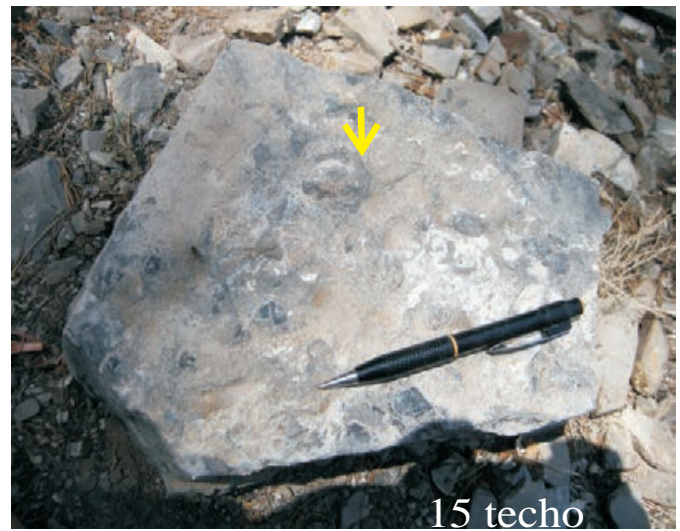

E

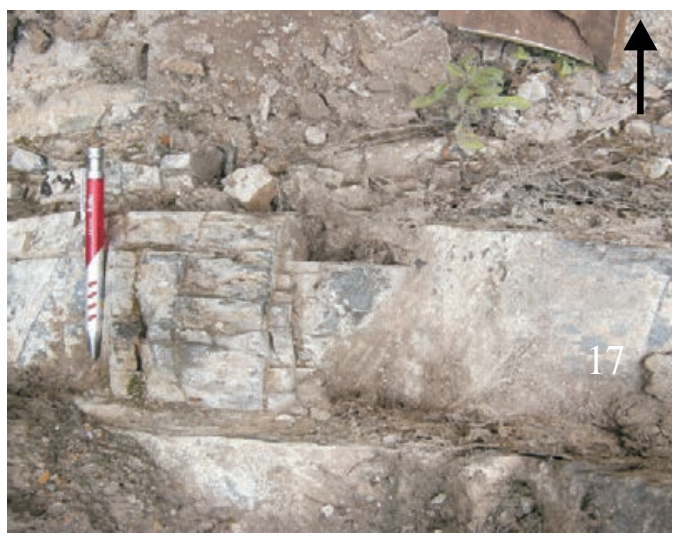

F

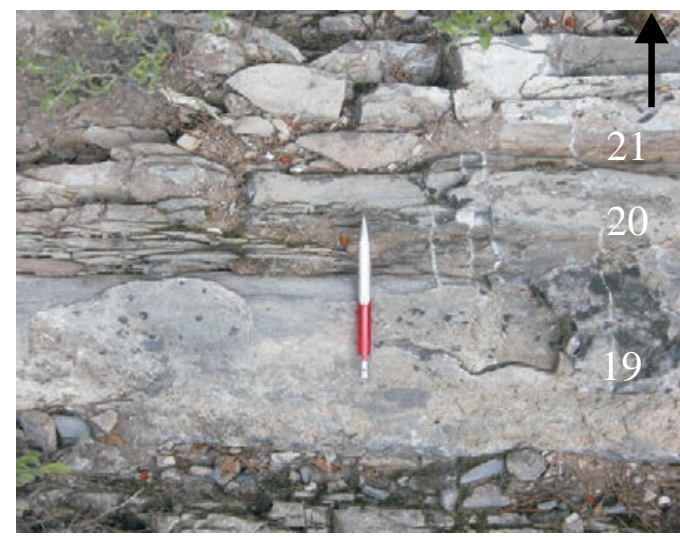

Figura 5 Detalle macroscópico de los cuerpos sedimentarios (estratos, horizontes) con acumulaciones fosilíferas en el Perfil Cañón de San Matías (MZ-3). (A) Detalle que muestra en espesor la acumulación fosilífera de la parte superior del horizonte 14F techo. (B) Superficie de estratificación del horizonte $14 \mathrm{~F}$ techo con acumulación de restos fósiles localmente imbricados (flecha amarilla en pavimento de conchas). (C) Estratificación con posible retoque diagenético (techo localmente convexo) en acumulación de restos fósiles en el horizonte 15 techo. (D) Detalle del pavimento de restos fósiles en la superficie de estratificación del horizonte 15 techo, con ejemplo de imbricación (flechas amarillas). (E) Aspecto tabular del estrato 17 de composición más limolítica y notable disminución en macrofósiles. (F) Estratos, 19 al 21 de composición limolítica ligeramente calcárea, aspecto tabular y mantenimiento de la notable disminución en macrofósiles; nótese efectos diagenéticos en los contactos con los interlechos menos carbonatados. Flechas negras indican la polaridad estratigráfica. Portaminas $(15 \mathrm{~cm})$ como escala. 

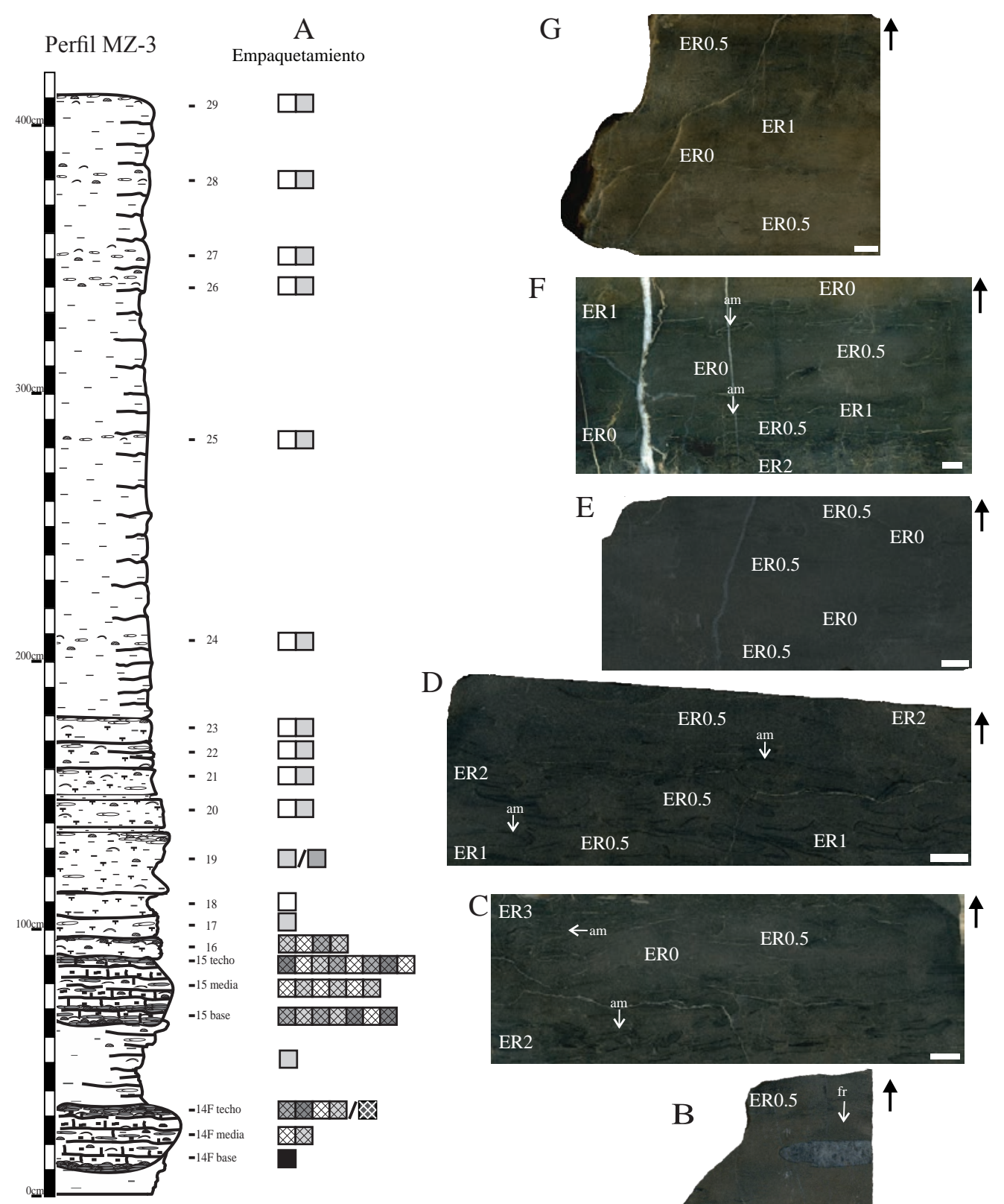

ERO国/ELO $\square$-Sin macroóósiles observables

ER0.5ख/EL0.5口-"Flotado"

ER1国/EL1 $\square$ - "Flotado" laminar

ER2国/ EL2 $\square$ - "Flotado" laminar con enclaves de empaquetamiento caótico

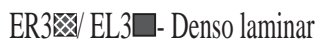

ER4- EL4—- Denso laminar con enclaves de empaquetamiento cático

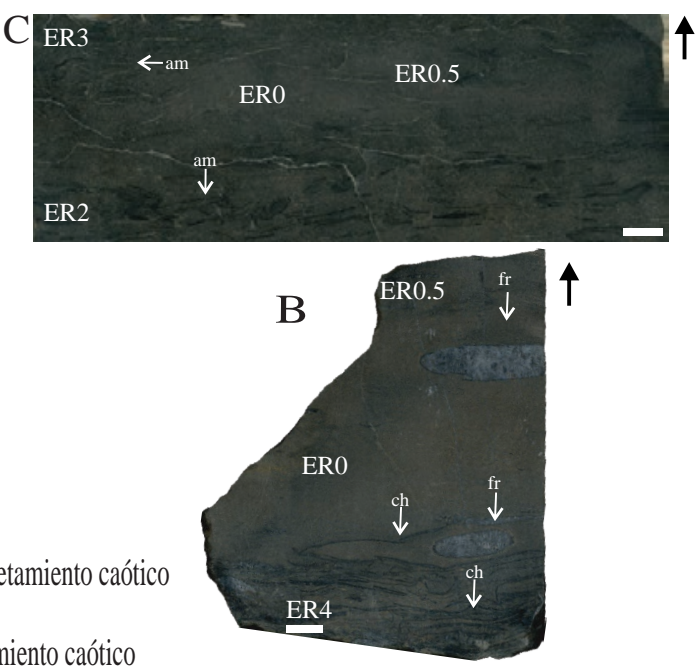

Figura 6 Tipos de empaquetamiento reconocidos en el Perfil Cañón de San Matías (MZ-3). (A) Variación del tipo de empaquetamiento en la sucesión estudiada (descripción detallada en el texto, sección 4.1-4.6). (B) Corte que muestra dos horizontes, la parte superior del $14 \mathrm{~F}$ base, donde se puede observar el relleno recristalizado del fragmocono (fr) y relleno de matriz en la cámara de habitación (ch); el horizonte 14F media muestra ejemplares recristalizados. Diferentes tipos de empaquetamiento en los horizontes $14 \mathrm{~F}$ techo (C, sólo se representa la parte media y alta del horizonte), 15 base (D), 15 media (E), 15 techo (F), y estrato 16 (G). Nótese la variación del empaquetamiento de base a techo. Todos los cortes se presentan en el plano correspondiente al espesor en afloramiento, excepto (B), (D) y (G) obtenidos en plano vertical perpendicular a la dirección de la estratificación. Flechas blancas para indicar ammonites (am), cámara de habitación (ch) y fragmocono (fr). Flechas negras, indican la polaridad estratigráfica. Barra $1 \mathrm{~cm}$. Las imágenes fueron modificadas digitalmente para reconocer los rasgos empaquetamiento. 
disminuye al $26 \%$. Lo mismo se observa en aptychi, ya que en el horizonte $14 \mathrm{~F}$ base representan el $17 \%$ y se incrementa hasta un $30 \%$ (estrato 26), mientras que los bivalvos varían del $28 \%$ al $13 \%$ en los primeros $2 \mathrm{~m}$, y en los $2 \mathrm{~m}$ suprayacentes alcanzan $39 \%$ (Figura 7).

Entre los ammonites, los glochiceratinos son mayoritarios $(34 \%)$, seguidos de haploceratinos (25 $\%$ y en menor proporción taramelliceratinos (8 $\%)$; componentes raros son los ataxioceratinos (2 $\%$ ); un porcentaje considerable de fragmentos no permiten la identificación precisa (29\%).

Entre los organismos bentónicos los bivalvos son dominantes (18\% del total de invertebrados); un porcentaje elevado $(48 \%)$ no fueron determinados por su deficiente preservación. Buchídos (17 $\%$ ), inocerámidos (15\%), y en menor proporción pseudomonotidos $(8 \%)$, arctídos $(5 \%)$, astartidos $(5 \%)$ y lucinidos $(2 \%)$ conforman la asociación identificada. La presencia de gasterópodos es ocasional $(2 \%)$.

Fragmentación, articulación y orientación. La fragmentación es alta, con un índice de fragmentación con valores de 60 a 80 \%. Las conchas de bivalvos y los aptychi presentan una desarticulación del $100 \%$, mientras que la posición en ambos casos fue mayoritariamente convexa, alcanzando un $68 \%$, y el $32 \%$ en posición cóncava (sin considerar casos de orientaciones verticalizadas). La orientación más frecuente es concordante o paralela a la estratificación (95\%), la oblicua representa el $4 \%$, y la posición verticalizada es rara y solo se presenta en algunos bivalvos desarticulados y en los raros registros de gasterópodos $(1 \%)$ que no presentan la posición de vida (Figura 8).

Tamaño, conservación y "corrasion" de los restos. El tamaño predominante de los restos es $<30 \mathrm{~mm}$ (Figura 8), los macrofósiles con talla más grande (55 a $115 \mathrm{~mm}$ ) son los ammonites, en particular los ataxioceratinos-lithacoceratinos y algunos ejemplares de glochicerátidos. La conservación de huellas o impresiones $(31 \%)$ se registró principalmente en los niveles limolíticos, y en molde interno (69\%) se presentaron en los niveles más calcáreos; en ningún ejemplar se conservó concha original aragonítica, solo neomórficas con recristalización variable. El índice de "corrasion" (Olóriz et al., 2002b) es alto 62 a 82 \% (Figura 8).

\subsection{BIOESTRATIGRAFÍA}

Los datos bioestratigráficos obtenidos en el perfil, basados en el estudio taxonómico de la fauna de ammonites recolectada con estricto control estratigráfico de resolución centimétrica, ha permitido corroborar la edad propuesta por Villaseñor et al. (2000, 2012), correspondiente a la parte media del Kimmeridgiano tardío, abarcando la Zona Eudoxus de la escala biocronoestratigráfica de la Provincia Submediterránea para Europa (Hantz pergue et al., 1997). En la parte alta del perfil (estrato 26) se recolectó fauna de Hybonoticeras típica de la Zona Beckeri (Figura 9).

El registro de Glochiceras (Coryceras) carinatum (Del Castillo y Aguilera, 1895) y Glochiceras (C.) cf. $c a^{-}$ rinatum (Del Castillo y Aguilera, 1895) en la parte basal de la sección estudiada, y su rango conocido en otros perfiles de norte-centro de México (Villaseñor et al., 2000, 2012) favorece la propuesta de reconocimiento de la subbiozona de Glochiceras (Coryceras) carinatum.

El registro paleontológico de los niveles con concentraciones de conchas es estratigráficamente discontinuo y no se han podido reconocer diferencias bioestratigráficamente significativas en las asociaciones registradas (Figura 9). En consecuencia, no se puede estimar el time-averaging en términos bioestratigráficos y se asume que el potencial de retrabajamiento de los restos está por debajo del potencial de resolución biostratigráfica a nivel de la escala biozonal existente para México.

\subsection{ANÁLISIS DE MICROFAGIES}

Las microfacies analizadas en el perfil del Cañón de San Matías (MZ-3) revelan dos tipos de texturas relacionadas con las biofábricas de empaquetamiento -floatstone y wackestone- en función de una matriz con mayor y menor tamaño en el rango de los limos, respectivamente: 


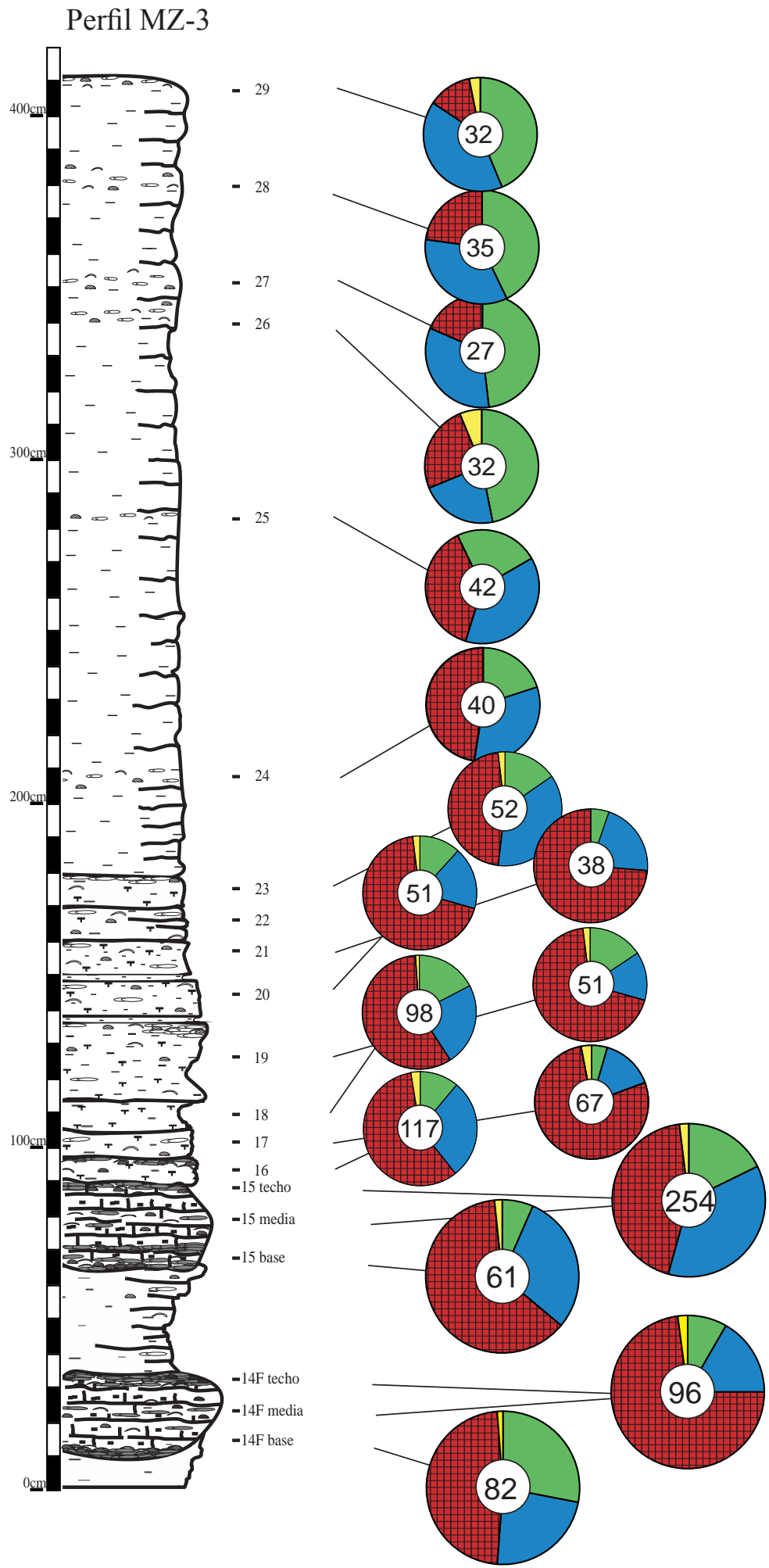

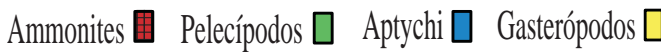

Figura 7 Espectros faunísticos con indicación del total de restos identificados taxonómicamente por horizonte, estrato y nivel. No se incluyen restos sin identificación taxonómica a nivel de género o especie. Las cifras indican el número total de restos identificados en cada caso. Detalles en el texto. 


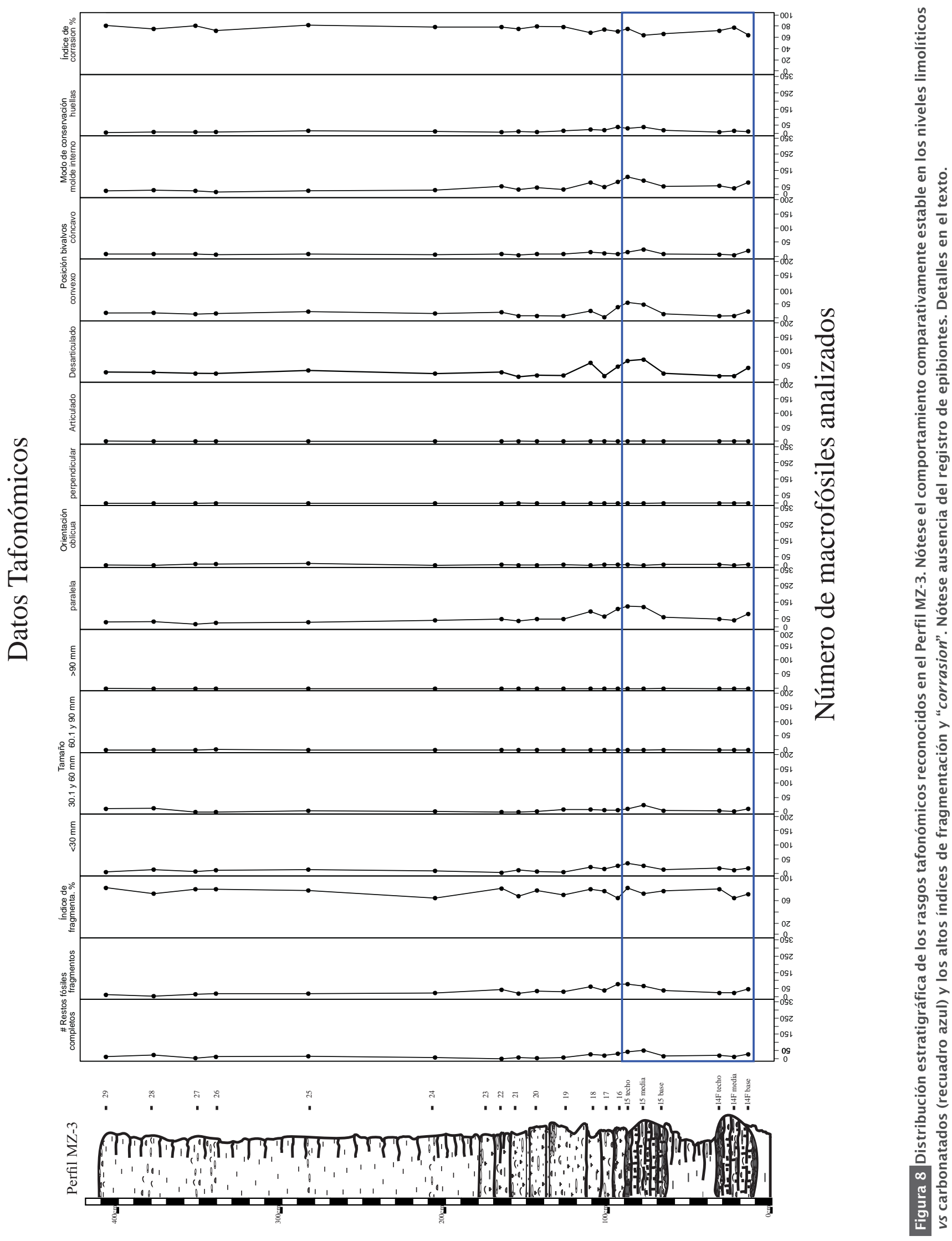




\section{LEYENDA}

Primer registro (FAD - Firts A ppearance D atum)

Último registro (LAD - LastA ppearance Datum)

Perfil M Z-3

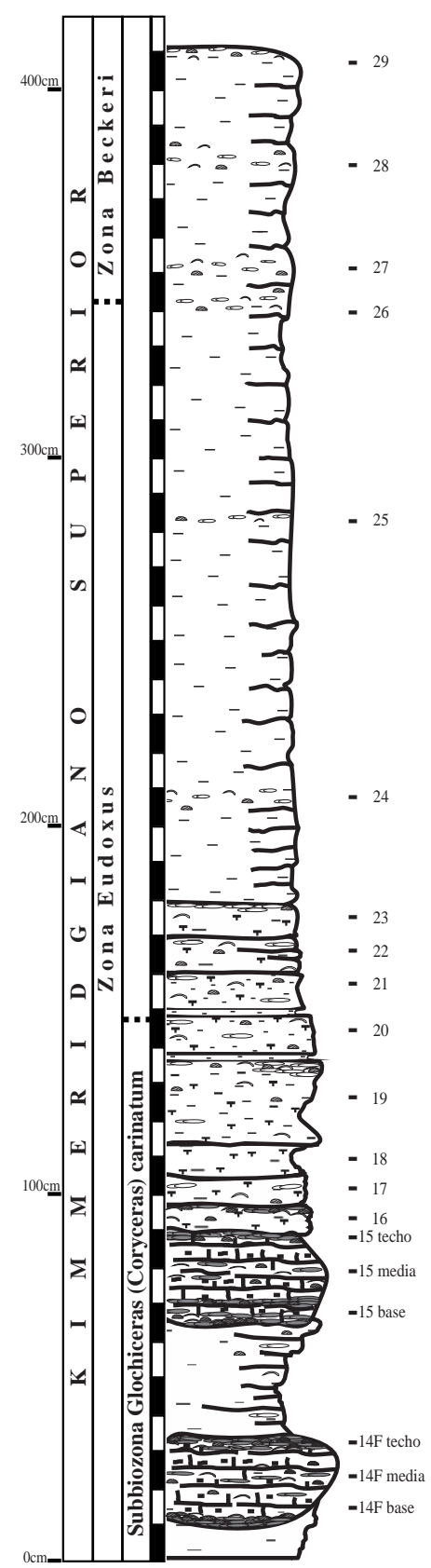

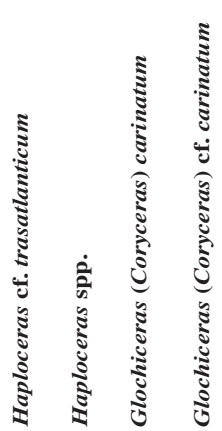
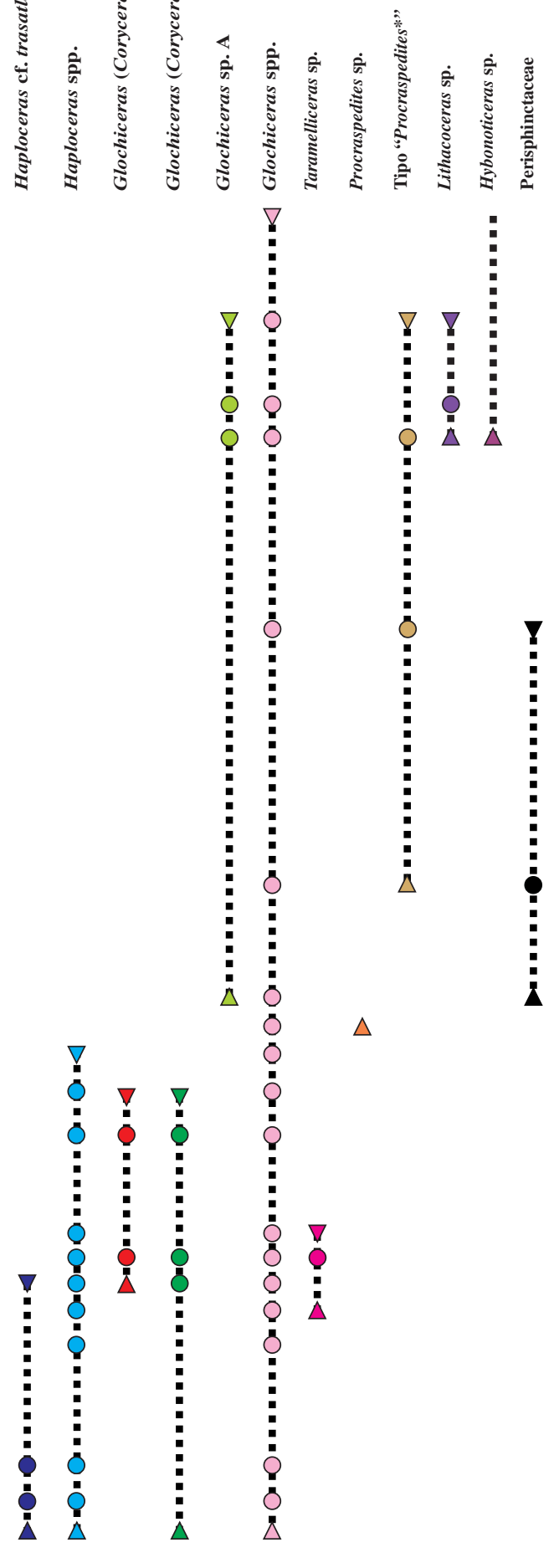

$\triangle$

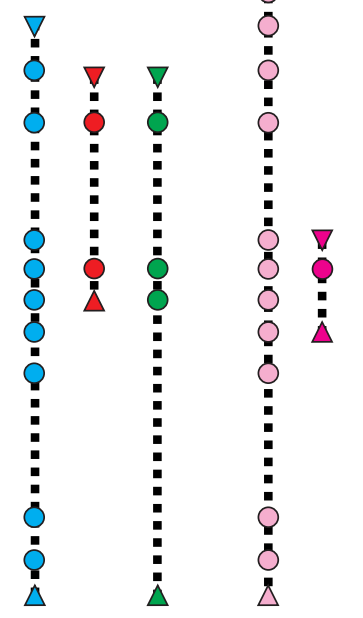

Figura 9 Distribución bioestratigráfica de la fauna de ammonites en el Perfil Cañón de San Matías (MZ-3). Nótese el registro discontinuo. Los círculos indican el estrato u horizonte donde se registró el taxón indicado. Referencia a las zonas Eudoxus y Beckeri del estándar europeo Submediterráneo para clarificar la correlación biocronoestratigráfica. 
i. Floatstone-wackestone de bioclastos con parches locales de packstone (Figura 10). Matriz de calcisiltita con tamaño de grano de limo muy grueso a medio (80 a $30 \mu \mathrm{m})$. Los bioclastos se presenten embebidos en la matriz, por lo que la textura es matriz-soportada, aunque hay empaquetamientos locales comparativamente densos, grano-soportados (parches locales de packstone), en los que se pueden observar pequeños bivalvos articulados y fragmentos de moluscos, como ammonites, aptychis, bivalvos, así como braquiópodos. Los clastos más grandes corresponden a fragmentos de moluscos, entre los que se pueden reconocer ammonites (am) de tamaño mayor a $1 \mathrm{~cm}(2$ $\%$ ); los braquiópodos (br) pueden alcanzar un tamaño de $1.2 \mathrm{~cm} \mathrm{(3 \% );} \mathrm{aptychi} \mathrm{(apt)} \mathrm{mues-}$ tran tamaño más variado, $0.1 \mathrm{~mm}$ a $1.5 \mathrm{~cm}(5$ $\%$ ). Los fragmentos de bivalvos (fbi) muestran un rango de tamaño del $0.1 \mathrm{~mm}$ a $2 \mathrm{~cm}$ (8 $\%$. También se han reconocido otros bioclastos tamaño limo a arena fina como bivalvos articulados (bi) de $50 \mu \mathrm{m}$ a $200 \mu \mathrm{m}$, correspondientes a fases larvarias avanzadas $(10 \%)$. Radiolarios (rad), de $80 \mu \mathrm{m}$ a $150 \mu \mathrm{m}$, calciesferas (cal) de $60 \mu \mathrm{m}$ a $120 \mu \mathrm{m}, \mathrm{y}$ ammonitellas (am) con tamaño de $100 \mu \mathrm{m}$ a $110 \mu \mathrm{m}$; éstos tres últimos grupos son los bioclastos menos abundantes (1\% cada grupo). No se observó microperforación (microboring) ni epibiontes macro-microscópicos. Existen parches de packstone en donde los bioclastos presentan contacto puntual y longitudinal. Los bioclastos están parcialmente silicificados y es notable su recristalización.

ii. Floatstone-wackestone de radiolarios (Figura 11). Matriz de calcisiltita con tamaño de grano de limo medio a grueso (30 a $60 \mu \mathrm{m})$. Los bioclastos se presentan embebidos en la matriz, por lo que la textura es matriz-soportada. Los clastos más grandes que se observan en sección delgada son fragmentos de moluscos (fm), incluyendo bivalvos (fbiv) y aptychi (apt) cuando es posible determinar su origen; en otro caso se refieren como no determinados (nd).
Los fragmentos de molusco alcanzan tamaños de arena muy gruesa a rudita (1 a $7 \mathrm{~mm})$ con orientación preferencial oblicua, distribución dispersa y abundancia de 3 a $5 \%$. Los bioclastos más comunes son radiolarios ( $\mathrm{ra}$ ) tamaño limo grueso a arena fina (80 $\mu \mathrm{m}$ a $200 \mu \mathrm{m})$, con abundancia de 10 a $15 \%$. También hay bivalvos articulados en fase larvaria (bi) con tamaño $50 \mu \mathrm{m}$ a $200 \mu \mathrm{m}(8-10 \%)$. Calciesferas (cal) muestran tamaño limo grueso a arena muy fina $(60 \mu \mathrm{m}$ a $120 \mu \mathrm{m})$ y abundancia $3-8$ $\%$. Se registraron escasos foraminíferos (for?), quistes de dinoflagelados (qd?) y litoclastos (lit?) cuyas asignaciones resultaron tentativas debido a la recristalización de los bioclastos. Los foraminíferos presentan un tamaño hasta $110 \mu \mathrm{m}$ (arena muy fina), mientras que los litoclastos (lit?) hasta $80 \mu \mathrm{m}$ (ca. límite de limos muy gruesos a arenas muy finas). Un único resto de Saccocoma (sac) se identificó en el estrato MZ-3-17. No se observó microboring ni epibiontes micro-macroscópicos. En algunos casos los bioclastos están parcial o totalmente silicificados, siempre recristralizados, y existen corpúsculos de color marrón oscuro que se interpretan como restos ferruginizados de posible materia orgánica (mo).

\section{Interpretación}

En general, los sedimentos encajantes de la sucesión estudiada son limolitas grises desigualmente oscuras a pardas, arcillosas, poco calcáreas y de estratificación fina, agrupadas en cuerpos sedimentarios que de manera recurrente conforman niveles compuestos en el afloramiento, a veces con aspecto local concrecional si localmente se encuentran enriquecidas en carbonatos. En las rocas encajantes la litofacies limolítica persiste sin estructuras sedimentarias otras que laminaciones sutiles, más evidentes en los tramos superiores de coloración crema por intemperismo. La ausencia de intercalaciones de otro tipo de depósitos se interpreta como evidencias de condiciones ambientales de depó- 
A

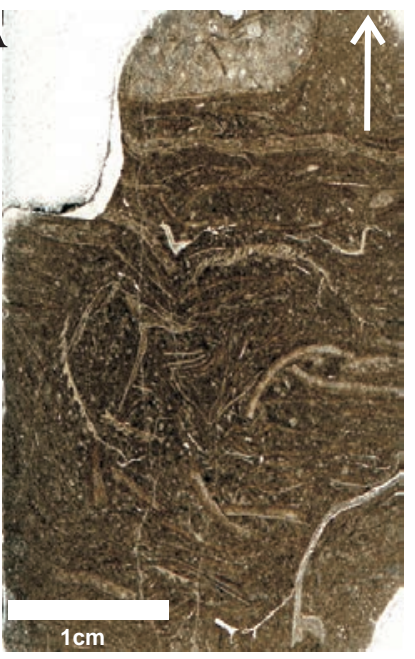

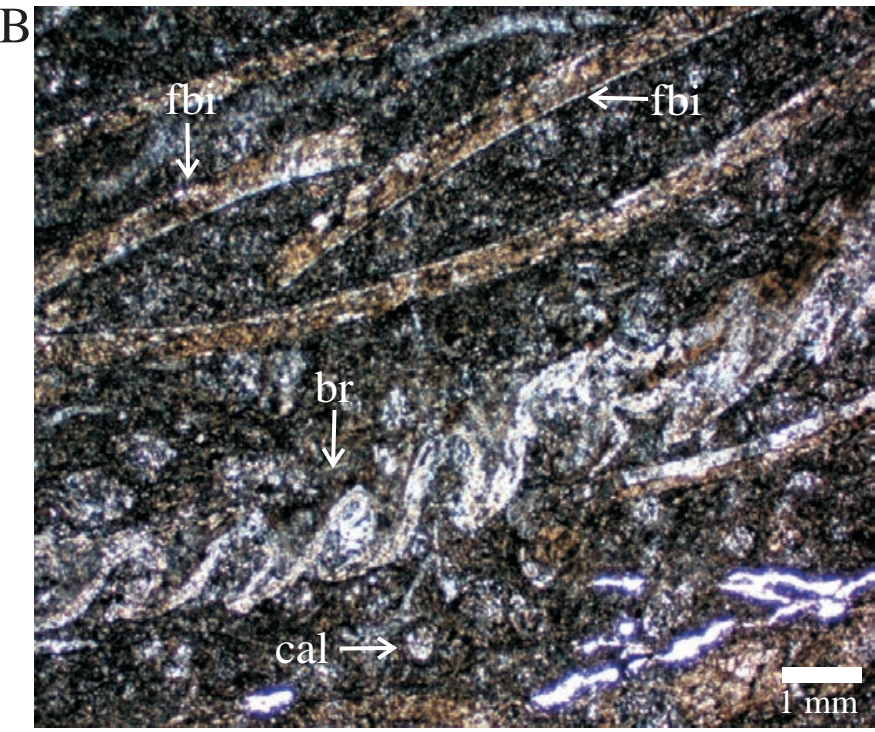
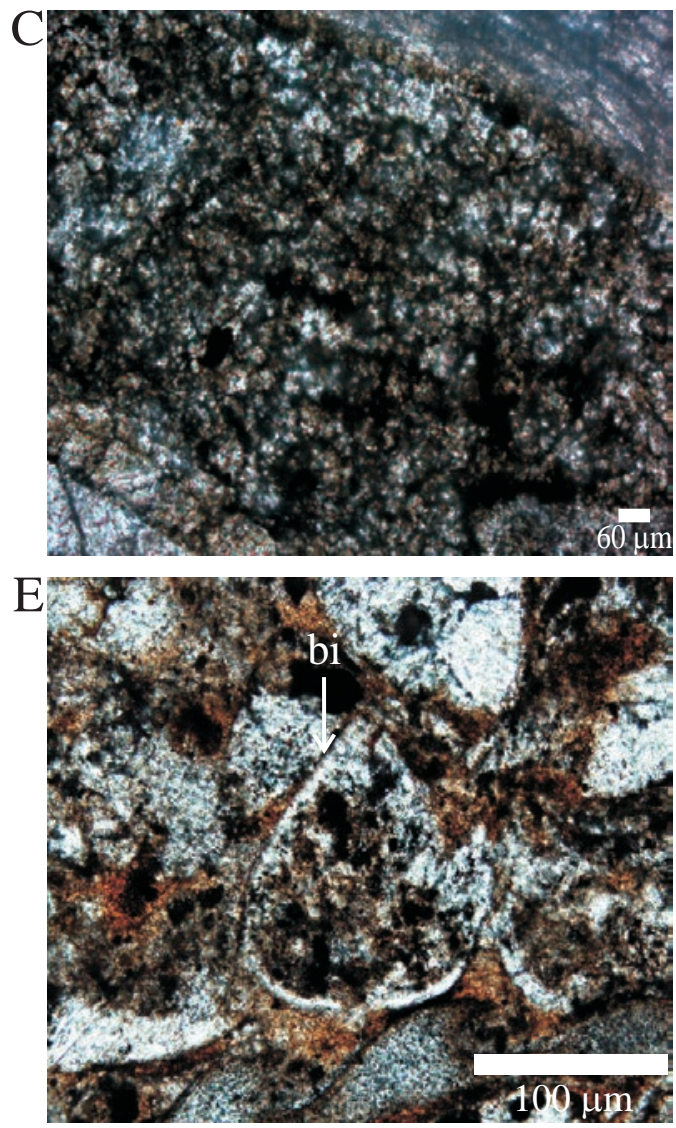
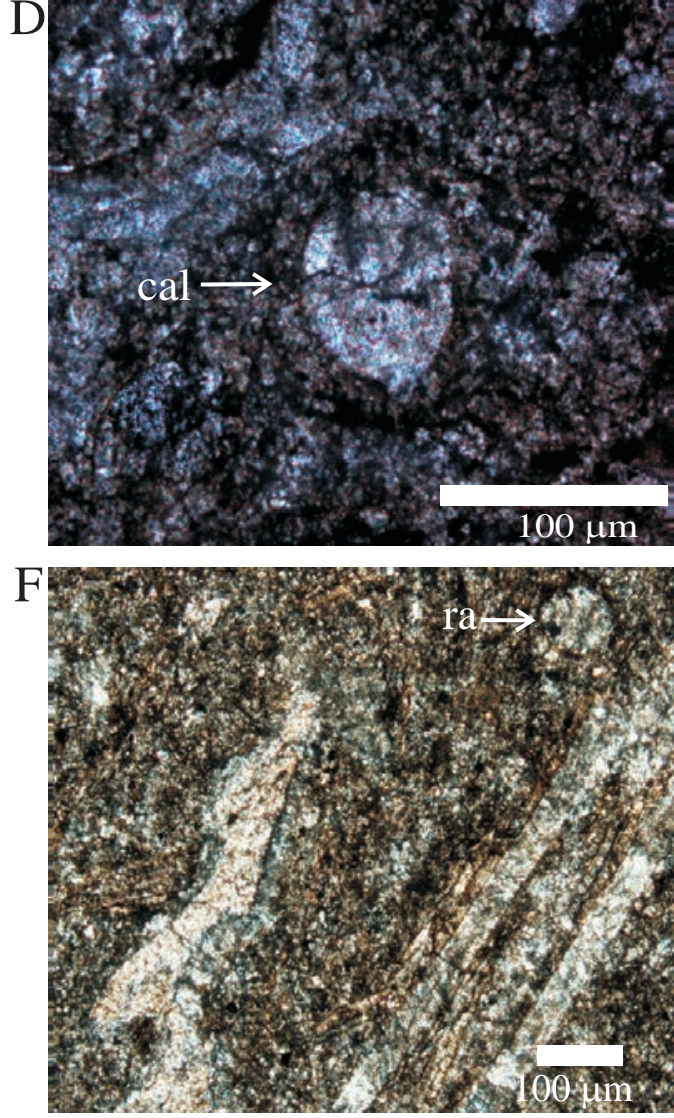

Figura 10 Fotomicrografías que representan la microfacies floatstone-wackestone de bioclastos con parches locales de packstone. Todas las imágenes corresponden al horizonte $14 \mathrm{~F}$ base. (A) Sección delgada en plano de corte perpendicular a la estratificación, mostrando organización caótica de bioclastos en packstone. (B) Fragmentos de bivalvos (fbi) y braquiópodo (br) con orientación oblicua. (C) Matriz de microesparita y calcisiltita con tamaño de grano de 30 a $80 \mu \mathrm{m}$. (D) Calciesfera (cal). (E) Posible bivalvo en fase larvaria avanzada (bi). (F) Radiolario (ra). Nótese la recristalización acentuada de los bioclastos y la presencia de envueltas y corpúsculos de posible origen orgánico. Todas las imágenes con luz transmitida, y corresponden a la sección delgada que se ilustra en A. La imagen en $\mathrm{F}$ corresponde a una ampliación puntual en un parche de biofabrica caótica. 

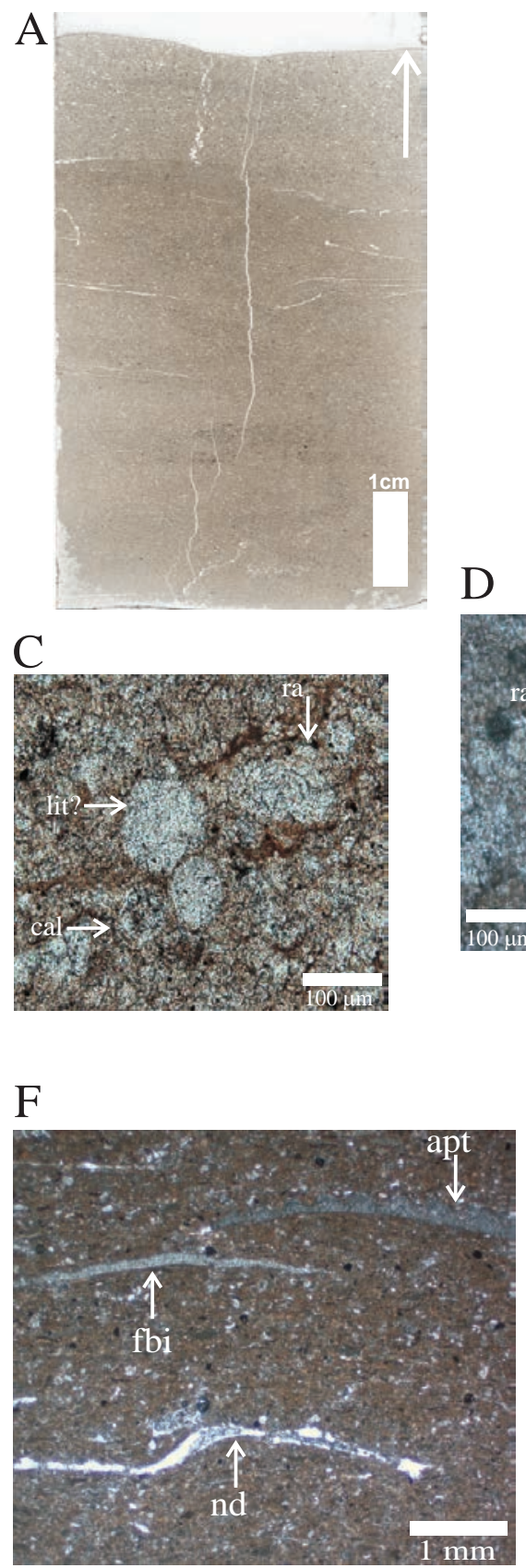

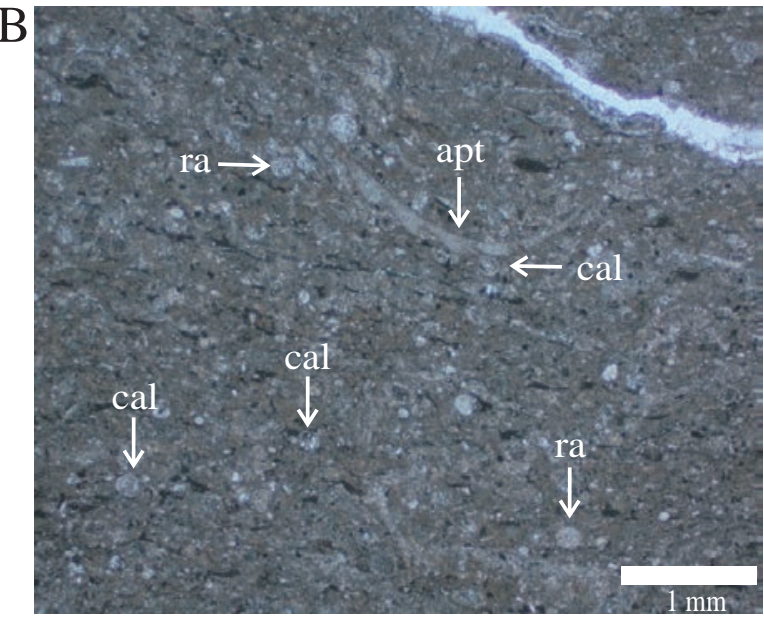

E

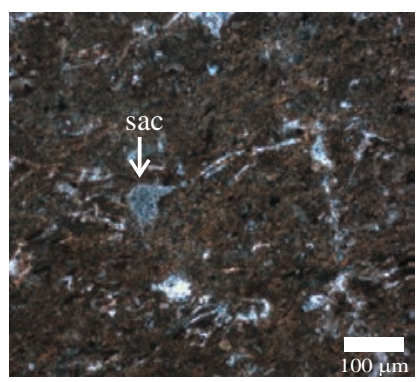

G

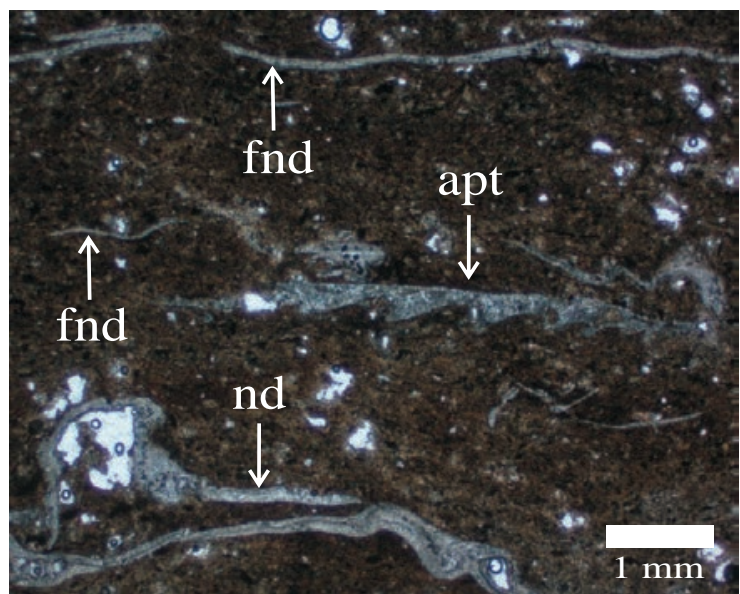

Figura 11 Fotomicrografías que representan la microfacies floatstone-wackestone de radiolarios. (A) Sección delgada, en plano de corte perpendicular a la estratificación, mostrando microlaminación sedimentaria con ondulaciones y acuñamientos laterales (¿laminación cruzada, microripples?) en matriz fina con pequeños granos de cuarzo; horizonte MZ-3 15 techo. (B) Radiolarios (ra), Calciesferas (cal) y aptychus (apt); nótense bioclastos parcialmente silicificados; estrato 16. (C) Calciesfera (cal), posible radiolario espumelárido mostrando estructura concéntrica (o espiral) densa, formada por capas medulares internas y la cortical externa (ra) y litoclasto (lit?); horizonte 14F media. (D) Radiolario (ra) mostrando configuración esquelética como en C; horizonte 14F media. (E) Saccocoma (sac); estrato 17. (F) Aptychus (apt), fragmento de bivalvo (fbi) y fragmento no determinado (nd). Nótese acentuada recristalización de bioclastos y matriz, silicificación de algunos bioclastos, y la existencia de cuerpos filamentosos discontinuos, corpúsculos y envueltas ferruginosas de posible origen orgánico; estrato 20. (G) Aptychus (apt), filamentos no determinados (fnd) frecuentemente interpretados como restos de posibles bivalvos pelágicos o flotadores en fondos blandos, y fragmento no determinado (nd); estrato 17. Todas las imágenes con luz transmitida, excepto (E) con luz polarizada (giro $90^{\circ}$ ). Nótese algún caso de orientación localmente oblicua de fragmentos. 
sito de energía relativamente baja, compatibles con interrupciones recurrentes de mayor energía que ocasionaron procesos erosivos, asumiendo un contexto de tasa de sedimentación baja con tasa de acumulación moderada a alta (sensu Gómez y Fernández-López, 1994) según los casos. Tanto en las rocas encajantes como en la sucesión estudiada, la ausencia de bentos diversificado in situ, la ausencia de bioturbación macroscópica, y el contenido en materia orgánica evidenciado por la coloración, el olor fétido y las microfacies (sucesión estudiada de floatstone-wackestone de bioclastos con parches locales de packstone, y wackestone de radiolarios, ambas con matriz calcisiltítica en el rango de limos de tamaño medio a grueso y abundantes ferruginizaciones relacionadas con restos de materia orgánica, son coherentes con escasa oxigenación, al menos para las aguas del fondo, en coincidencia con interpretaciones sobre la composición del bentos registrado en el perfil Cañón de San Matías (De la Mora et al., 1999a-b, 2000). Estimaciones derivadas de la composición de las asociaciones de macrobentos apuntan hacia profundidades neríticas (Schumann, 1985, 1988; Olóriz, 1987; Olóriz et al., 1988; 1990; 1993, 1997, 2000; Villaseñor, 1991). La conservación neomórfica de carcasas de ammonites en los niveles más carbonatados, y también de manera excepcional en los limolíticos, implica profundidades en el rango de preservación de la aragonita y menores que el de implosión para conchas de ammonites (> $400-700 \mathrm{~m}$ en Olóriz et al., 2002a; incluso de $150 \mathrm{~m}$ a $400 \mathrm{~m}$ en la mayoría de los casos según índices de resistencia del sifúnculo para Westermann, 1982, y de 100 - 250 m para análogos nautílidos en Hewitt et al., 1991). La ausencia o extrema escasez de ammonites típicos en asociaciones epioceánicas (p.ej., litocerátidos y phylloceratidos) refuerza la interpretación de profundidades neríticas y contrasta con el contexto de profundidades batiales-abisales propuesto por Pessagno y Martin (2003). Ejemplos de silicificación incipiente evidencian efectos diagenéticos derivados de la disolución de plancton silíceo (p.ej., radiolarios) y, tal vez, de actividad volcánica regional (revisión en Olóriz y Villaseñor,
2017). La ausencia de registro de deslizamientos gravitatorios sinsedimentarios en los sedimentos encajantes, así como en el resto del perfil, permite asumir fondos de relieve suave en las proximidades del entorno representado por el perfil Cañón de San Matías, lo que resulta especialmente relevante para la interpretación del cambio de facies entre los carbonatos del Grupo Zuloaga y las limolitas con un escaso componente carbonatado del Grupo La Casita, y permite reducir las posibilidades de registro para algunos tipos de eventitas (depósitos locales relacionados con regímenes de flujo turbulento; Seilacher, 1982). En consecuencia, se interpreta un contexto paleoambiental de plataforma mixta siliciclástica-carbonatada, ubicado en sectores de plataforma media a externa, que será matizado a partir del estudio de las concentraciones fosilíferas (shell beds) reconocidas.

$\mathrm{El}$ análisis de los horizontes enriquecidos en fósiles revela como rasgo relevante su registro discontinuo, independientemente de la biofábrica y densidad de empaquetamiento (tipos ER0.5 a ER4), así como del espesor del cuerpo sedimentario en el que se encuentren incluidos. Los horizontes enriquecidos en fósiles pueden catalogarse como pavimentos (ER1-ER2) y capas de conchas (ER3-ER4) (pavements y shell beds sensu Kidwell et al., 1986). Los patrones de organización de estos horizontes vienen establecidos por sucesiones de tipos de empaquetamiento y la intercalación "irregular" de episodios de depósito desprovistos de macrofósiles (ER0) y/o empobrecidos en restos macroscópicos (ER0.5). Dichos patrones son coherentes con secuencias de redepósito ligadas a eventitas (eventites sensu Seilacher, 1982) que muestran empaquetamiento de densidad decreciente cuyas variaciones en el patrón se consideran desviaciones de una secuencia tipo: (i) horizonte con empaquetamiento comparativamente denso de bioclastos; (ii) empaquetamiento nulo; y (iii) empaquetamiento incipiente de restos "flotados" en la matriz. La secuencia de redepósito tipo se registra entre eventos de energía relativa alta en relación con superficies hiatales o erosionales cuya expresión es sutil a moderada, y acumulación de 
bioclastos con empaquetamiento mínimo tipo ER2 sobre un cuerpo sedimentario que representa las condiciones eco-sedimentarias normales o de "background" para el enclave estudiado, de acuerdo con el registro estratigráfico (empaquetamientos tipo ER0.5-ER1 según los casos). Desviaciones del patrón tipo responderán a los efectos de procesos erosivos y/o de aventamiento (winnowing), con o sin sobreimposición de cuerpos sedimentarios retrabajados (redepositados con mayor o menor transporte). Mientras que el desarrollo vertical y lateral de los horizontes enriquecidos en fósiles es esencialmente genético, relacionado con los procesos ambientales-sedimentarios involucrados y la fisiografía del fondo, su reconocimiento local dependerá de las condiciones de afloramiento. El patrón de la secuencia de redepósito tipo responde a eventos energéticos (huracanes, tormentas, aventamientos), disipación progresiva pero rápida de la energía, y retorno a condiciones eco-sedimentarias normales para el enclave de depósito de referencia. En principio, y en ambiente de plataforma, el patrón reconocido es coherente con eventos de tormenta y/o aventamiento, cuya recurrencia y variaciones en la energía efectiva (combinación de energía y distancia relativas) forzaría el registro sedimentario identificado en el afloramiento estudiado del perfil Cañón de San Matías. Consideraciones tafonómicas, sedimentológicas y estratigráficas sirven para matizar la interpretación de los procesos relacionados con el depósito de los distintos tipos de horizontes enriquecidos en fósiles, de acuerdo con la biofábrica y tipo de empaquetamiento. La compactación sedimentaria ha sido tenida en cuenta, aunque su estimación precisa no es abordada en este trabajo.

La interpretación de las siguientes muestras es ilustrativa y sirve a la aproximación al contexto eco-sedimentario en una casuística diferenciada: parte superior del horizonte 14F (Figura 6B); parte superior del horizonte $14 \mathrm{~F}$ techo (Figura $6 \mathrm{C}$ ); parte superior del horizonte 15 base (Figura 6D); horizonte 15 media (Figura 6E); horizonte 15 techo (Figura 6F); y estrato 16 (Figura 6G). En todos los casos se asume acentuación del empaquetamien- to por compactación, lo que puede deducirse del aplastamiento observado en ammonites (moldes internos y zonas rellenas de sedimento en carcasas con preservación de concha neomórfica). Igualmente, en todos los casos se asume que el registro descrito expresa el producto del último evento en el caso de horizontes con acumulación compleja de conchas.

\subsection{MUESTRA DE LA PARTE INFERIOR Y MEDIA DEL HORIZONTE 14F (FIGURA 6B)}

Se reconoce empaquetamiento basal tipo ER4, que representa la acumulación de mayor densidad de conchas identificada, con espesor de pocos centímetros y se interpreta como una capa de conchas (shell bed). Las intercalaciones limolíticas entre láminas de restos se interpretan como remanentes de depósitos finos entre episodios de aventamiento, como mínimo, y evidencia el carácter complejo del horizonte con superposición de eventos de aventamiento que generaron los pavimentos de conchas. Episodios de alta tasa de acumulación se relacionan con el registro de ammonites con cámaras de habitación rellenas de sedimento (mostrando deformación dúctil y frágil) y fragmoconos recristalizados (preservados en volumen sin evidencias de compresión). La alta fragmentación con bordes angulosos es compatible con transporte limitado y exposición sobre el fondo, ambos probablemente ligados a repetidos pulsos de incrementos de energía que determinaron enclaves con orientación caótica, y aventamiento de restos. Las capas laminadas con restos en posición convexa dominante implican retoques (vuelco) por corrientes débiles relacionadas, o ligeramente posteriores, al evento energético más reciente. En ausencia de registros de edad diferente, se asume promediado temporal de hábitat o intra-habitat (within-habitat time averaging sensu Kidwell y Bosence, 1991), por debajo del potencial de resolución bioestratigráfica.

El horizonte suprayacente con empaquetamiento ER0 representa un remanente del redepósito de sedimento aventado más reciente y genéticamente ligado al mismo evento que forzó el empaqueta- 
miento denso (ER4) previo. El registro de empaquetamiento ER0 implica disipación de la energía de flujo con depósito relativamente rápido de un cuerpo sedimentario cuyo espesor en el afloramiento debe considerarse aparente (de expresión local, puntual). La tasa de acumulación fue suficientemente rápida para favorecer el enterramiento de conchas de ammonites sin relleno sedimentario (posible fragmocono recristalizado y sin comprimir); alternativamente, el ejemplar identificado experimentó retrabajamiento (reworking) con pérdida de la cámara de habitación. El horizonte superior con empaquetamiento tipo ER0.5 se interpreta como el registro del aporte de conchas al fondo en condiciones eco-sedimentarias normales para el enclave estudiado (sedimentación de "background"). Dichas condiciones sucedieron al intervalo de continua, pero no progresiva, disipación de la energía que configuró la capa de conchas compleja (composite/multiple-event concentration sensu Kidwell, 1991) y el redepósito rápido con sedimento remanente del material aventado.

La sucesión de horizontes con empaquetamientos tipo ER4-ER0-ER0.5 representan una secuencia de redepósito compleja y completa, al incluir a techo el registro de las condiciones eco- sedimentarias normales para el enclave estudiado. No se han observado cuerpos sedimentarios con empaquetamiento ER0-ER0.5 que fosilizaran comunidades bentónicas en posición de vida o especialmente bien preservadas.

\subsection{MUESTRA DEL HORIZONTE 14F TEGHO (FIGURA 6C)}

Muestra de interés especial porque registra el techo del estrato. Indicios de imbricación en el empaquetamiento basal tipo ER2 implican acción de corrientes sobre varios pavimentos de conchas separados por hiladas de sedimento pobre en restos. Directamente encima, empaquetamiento ER0 (fase final del evento registrando redepósito de remanentes del material fino aventado) y posteriormente empaquetamiento ER0.5 que registra el retorno a condiciones eco- sedimentarias normales para el enclave estudiado, condiciones de "background". Nuevo evento más energético que genera una capa de conchas ("shell bed") con empaquetamiento denso tipo ER3, con enclaves de orientación caótica de restos forzados por condiciones de mayor energía (flujo turbulento). Destaca la irregularidad de la base del horizonte ER3 que puede deberse al efecto combinado de irregularidad del fondo y compactación que pudiera haber distorsionado (enmascarado) una posible superficie erosiva de expresión sutil. Dado que el plano de corte es perpendicular a la dirección del estrato, los indicios de imbricación reconocible en el horizonte ER2 implicarían que el patrón de flujo tuvo componentes paralelos a la dirección de la estratificación en el afloramiento. Dado que la muestra registra el techo del estrato, la ausencia de comunidades bentónicas in situ puede interpretarse en relación con una discontinuidad erosiva, y el correspondiente hiato sin incidencia bioestratigráfica reconocida; alternativamente, podría responder al contexto de escaso o nulo desarrollo de bentos por condiciones de baja oxigenación. En conjunto, la parte superior del horizonte $14 \mathrm{~F}$ techo registra una sucesión de eventos de energía creciente.

\subsection{MUESTRA DE LA PARTE SUPERIOR DEL HORIZONTE 15 BASE (FIGURA 6D)}

En esta muestra se reconoce la distribución irregular del registro de eventos de depósito por comportamiento lateral diferenciado, incluyendo acuñamientos y enclaves de orientación caótica de restos. La sucesión mostrada indica registros de depósito con empaquetamiento propio de condiciones de energía relativa baja (ERl) y de condiciones normales para el enclave estudiado, de "background", bajo influencia de corrientes débiles y pausas, con acuñamiento lateral (ER0.5), indicando tendencias de energía decreciente y retorno a condiciones de depósito habituales de menor energía. La ausencia de registro de cuerpos sedimentarios resultantes de aventamiento (ER0) puede deberse a discontinuidades menores, y en ese caso el acuñamiento lateral de horizontes ER0.5 (p.ej., secuencia inferior) podría involucrar la pérdida del 
registro de un remanente del cuerpo sedimentario aventado (ER0), evidenciado registro incompleto tal vez favorecido por la irregularidad del fondo en ausencia de superficies erosivas identificables. En las partes media y superior se muestra recurrencia de secuencias ER2-ER0.5 (incompleta la superior en esta muestra); en ausencia de indicios de discontinuidad (¿ipor compactación?), la ausencia de registros con empaquetamiento ER0 se interpreta como evidencia de secuencias incompletas por erosión o irregularidad del fondo. La energía de flujo correspondiente a estas secuencias correspondería esencialmente a flujo laminar con posibilidad de producir aventamientos locales.

\subsection{MUESTRA DEL HORIZONTE 15 MEDIA (FIGURA $6 \mathrm{E})$}

Se identifica recurrencia de condiciones eco-sedimentarias normales para el enclave estudiado (de "background" con empaquetamiento tipo ER0.5), interrumpidas por depósitos de grano fino (por aventamiento $=$ empaquetamiento ER0) ejemplificando secuencias incompletas comparativamente más distales respecto al área de aporte, solo sometidas a la influencia de la llegada de frentes de material fino aventado, situación análoga al efecto blanketing (sensu Brett et al., 2008) pero con matriz calcisiltítica. La muestra descrita pertenece al inicio de la sedimentación siliciclástica fina después del intervalo carbonatado (14F en Figura 6A).

\subsection{MUESTRA DEL HORIZONTE 15 TEGHO (FIGURA 6F)}

Se observa sucesión de secuencias completas de empaquetamiento (ER2-ER0-ER0.5 y ER1ER0-ER0.5) correspondientes a una sucesión de depósitos de niveles energéticos diferentes entre pausas de condiciones de depósito normales para el enclave estudiado (ER0.5), evidenciando una tendencia de energía decreciente que se estabiliza al nivel de la parte media y superior del horizonte 15 techo. La mayor o menor energía (y empaquetamiento) se relaciona con diferencias en la distancia y/o energía relativa del evento respecto al enclave de depósito representado. Asumiendo aventamiento seguido de corrientes de flujo laminar, se favorece la interpretación de disipación de la energía del evento y el retorno a las condiciones normales con presencia de corrientes débiles en el enclave estudiado.

\subsection{MUESTRA DEL ESTRATO 16 (FIGURA 6G)}

De base a techo la muestra revela condiciones eco-sedimentarias normales para el enclave estudiado (empaquetamiento ER0.5) interrumpidas por depósito de grano fino aventado (ER0), indicando la influencia de eventos relativamente distales (efecto análogo al blanketing sensu Brett et al., 2008) seguida de acumulación de restos con empaquetamiento relacionado con flujo de energía ligeramente superior al de condiciones normales (ER1) y retorno a condiciones eco-sedimentarias normales de menor energía (ER0.5) en el enclave estudiado. En consecuencia, el empaquetamiento tipo ER1 indicaría condiciones eco-sedimentarias normales con flujo laminar para el enclave estudiado.

En conjunto, se favorece la interpretación de las secuencias de eventitas como evidencias de fluctuaciones de energía, cuya ubicación en sectores proximales de la plataforma externa, en torno al nivel de base de tormentas, sería coherente con el predominio de laminaciones paralelas y/o suavemente oblicuas, así como con la ausencia de estructuras sedimentarias claramente relacionadas con el oleaje, al menos en aquellas secuencias que incorporan registro de condiciones eco-sedimentarias normales en el enclave estudiado. Complementariamente, se asume la posibilidad de episodios secundarios con ubicaciones algo más proximales en sectores distales de la plataforma media -ligeramente por encima, aunque próximo al nivel de base del oleaje- para aquellas secuencias incompletas y relacionadas con eventos de mayor energía, asumiendo que la ausencia de registros de estructuras sedimentarias de oleaje a techo correspondería a la pérdida de sedimentos por los eventos erosivos.

Transporte limitado, fragmentación alta, predo- 
minio de desarticulación, orientación concordante y "corrasion" alta, así como la ausencia de evidencias relevantes de selección de tamaños, colonización por epibiontes, y bioerosión, favorecen la interpretación de la dominancia del registro de eventos finales de aventamiento dominante, con efectos locales de retrabajamiento en los niveles de acumulación de conchas y exposición de restos sometidos a procesos esencialmente abióticos. La ausencia de macrobentos in situ y la escasez de microbentos son coherentes con un contexto de depósito en medio disaeróbico-poikiloaeróbico, al menos para las aguas próximas al fondo. En ausencia de transporte significativo, repetidos incrementos de exportación y acumulación de conchas debieron relacionarse con inestabilidad ecológica con efectos letales para las comunidades de invertebrados en la columna de agua. La frecuencia de eventitas en un medio ambiente de baja energía relativa implica que fue sometido a inestabilidades recurrentes de mayor energía, producidas por factores de desestabilización distantes, a las que deberían responder las comunidades de invertebrados en tiempo ecológico, por debajo del rango de resolución bioestratigráfica. La diversidad de tipos de empaquetamiento en las eventitas distales descritas implica variabilidad en la energía y/o distancias relativas de los factores desencadenantes de los eventos de depósito, situación que fue una constante paleoambiental en los sectores limítrofes entre la plataforma media y externa.

En último término, los factores involucrados con mayor probabilidad en el depósito de las eventitas distales fueron tormentas, y corrientes de fondo ligadas a tormentas, cuya energía y/o distancia relativa no favorecieron el registro de depósitos bajo condiciones de flujo oscilatorio, pero sí los aventamientos asociados a las fases de mayor energía, y sus efectos fueron acentuados por compactación debida a carga sedimentaria. La inexistencia de matriz arenosa y de gravas como evidencia de flujos densos permite desestimar la existencia de flujos turbidíticos sensu stricto. La homogeneidad de las litofacies sin registro de aportes exóticos impide considerar la existencia de flujos densos relacio- nados con incrementos de aportes continentales generados por tormentas en franjas costeras. La ausencia de figuras de deslizamiento sinsedimentario y de depósitos gravitacionales que incorporasen bloques, incluso durante los intervalos más energéticos, indica ausencia de pendientes acentuadas en las proximidades y de desestabilización de hipotéticos taludes próximos, sin desestimar la existencia de irregularidades menores en el fondo. Investigaciones en curso complementarán esta aproximación preliminar al estudio de concentraciones fosilíferas en el Jurásico Superior de México.

\section{Conclusiones}

La sucesión estudiada en el perfil Cañón de San Matías revela un contexto eco-sedimentario de baja energía, con depósito de limolita, cuyo contenido en carbonatos fue generalmente escaso a moderado. Son características la ausencia de superficies de erosión expresivas, de deslizamentos sinsedimentarios, de aportes exóticos, y de estructuras sedimentarias relacionadas con oleaje, así como el predominio de laminaciones paralelas y/o suavemente oblicuas. Las condiciones ecológicas incluyeron fondos disaeróbicos-poikiloaeróbicos con escaso registro de bentos in situ, e inestabilidades en la columna de agua que afectarían a las comunidades de organismos pelágicos y nectónicos generando incrementos en la exportación de restos al fondo.

Las concentraciones fosilíferas registradas se interpretan como eventitas distales, resultantes de procesos con energía efectiva variable cuya incidencia alcanzó sectores proximales de la plataforma externa, favoreciendo la concentración de material carbonatado en torno al nivel de base de tormentas. Secuencias de redepósito incompletas se relacionan con eventos de mayor energía efectiva.

De acuerdo con el registro estratigráfico, el patrón de la secuencia de redepósito tipo responde a eventos energéticos (huracanes, tormentas, aventamientos), posterior disipación progresiva pero rápida de la energía, y retorno a condiciones eco- 
sedimentarias normales para el enclave estudiado. La dinámica eco-sedimentaria propuesta para la sucesión estudiada en el perfil Cañón de San Matías responde a rupturas de equilibrio ambiental con periodos de recurrencia de rango temporal inferior al de la resolución bioestratigráfica en un intervalo del Kimmeridgiano tardío.

\section{Agradecimientos}

Esta investigación fue apoyada por los proyectos UNAM-DGAPA-PAPIIT IN105311-3, IN102016, y el Proyecto CGL2012-39835 del Ministerio de Industria Economía y Competitividad (MINECO), España. Este último proyecto y el Posgrado de Ciencias de la Tierra, UNAM; facilitaron la realización de una estancia de investigación de la primera autora en la Facultad de Ciencias de la Universidad de Granada. Se reconocen las aportaciones de los revisores, Sara Alicia Quiroz Barroso y Miguel Agustín Téllez Duarte. Se agradece a Marco Antonio Argáez Martínez su apoyo en campo, elaboración de láminas delgadas y superficies pulidas.

\section{Referencias}

Adatte, T., Stinnesbeck, W., Hubberten, H., Remane, J., 1991, Correlaciones multiestratigráficas en el límite JurásicoGretácico en el Noreste de México: Boletín de la Sociedad Geológica Mexicana, 51, 23-51.

Adatte, T., Stinnesbeck, W., Hubberten, H., Remane, J., 1993, Nuevos datos sobre el límite Jurásico-Cretácico en el Noreste y en el Centro de México: Boletín de la Sociedad Geológica Mexicana, 52, 11-14.

Adatte, T., Stinnesbeck, W., Remane, J., Hubberten, H., 1996, Paleoceanographic changes at the Jurassic-Cretaceous boundary in the Western Tethys, northeastern Mexico:
Cretaceous Research, 17, 671-689.

Aigner, T., Hagdorn, H., Mundlos, R., 1978, Biohermal, biostromal and storm generated coquinas in the Upper Muschelkalk: Neues Jahrbuch für Geologie und Paläontologie Abhandlungen, 157, 42-52.

Barboza-Gudiño, R., Hoppe, M., GómezAnguiano, M., Martínez-Macías, P., 2004, Aportaciones para la interpretación estratigráfica y estructural de la porción noroccidental de la Sierra de Catorce, San Luis Potosí, México: Revista Mexicana de Ciencias Geológicas, 21(3), 299-319

Brandt, D.S., 1989, Taphonomic Grades as a Classification for Fossiliferous Assemblages and Implications for Paleoecology: Palaios, 4, 303-309.

Brett, C.E., Kirchner, B.T., Tsujita, C.J., Dattilo, B.F., 2008, Sedimentary Dynamics in a Mixed Siliciclastic-Carbonate System: The Kope Formation (Upper Ordovician), Southwest Ohio and Northern Kentucky: Implications for Shell Beds Genesis in Mudrocks, en Holmden, C., Pratt, B.R. (eds.), Dynamics of Epeiric Seas: Sedimentological, Paleontological and Geochemical Perspectives, Geological Association of Canada, Special Paper 48, 406 p.

Buchy, M.C., 2008, New occurrence of the genus Dakosaurus (Reptilia, Thalattosuchia) in the Upper Jurassic of north-eastern Mexico, with comments upon skull architecture of Dakosaurus and Geosaurus: Neues Jahrbuch für Geologie und Paläontologie Abhandlungen, 249(1), 1-8.

Buchy, M.C., 2010, First record of Opthalmosaurus (Reptilia, Ichthyosauria) from the Tithonian (Upper Jurassic) of Mexico: Journal of Paleontology, 84(1), 149-155.

Buchy, M.C., Vignaud, P., Frey, E., Stinnesbeck, W., González-González, A.H., 2006, A new thalattosuchian crocodyliform from the Tithonian (Upper Jurassic) of northeastern Mexico: Comptes Rendus Palevol, 5, 785-794. 
Buchy, M-C., Young, M.T., Andrade, M.B., 2013, A new specimen of Cricosaurus saltillensis (Crocodylomorpha: Metriorhynchidae) from the Upper Jurassic of Mexico: evidence for craniofacial convergence within Metriorhynchidae: ORYGTOS, 10, 9-21.

Buffler, R.T., Sawyer, D.D., 1985, Distribution of crust and early history, Gulf of Mexico Basin: Gulf Coast Association of Geological Societies Transactions, 35, 333-344.

Burckhardt, C., 1906a, Géologie de la Sierra de Mazapil et Santa Rosa. X Congreso Geológico Internacional, Guía excursiones, $26 \mathrm{p}$.

Burckhardt, G., 1906b, La faune jurassique de Mazapil avec un appendice sur les fossiles du Crétacique inférieur: Boletín del Instituto Geológico de México, 23, 1-216.

Burckhardt, C., 1930, Étude synthétique sur le Mésozoïque Mexicain: Mémoires de la Société Paléontologique Suisse, 49-50, $1-280$.

Cantú-Chapa, A., 1969, Estratigrafía del Jurásico Medio-Superior del subsuelo de Poza Rica, Veracruz (Área de Soledad-Miquetla): Revista del Instituto Mexicano del Petróleo, 1(1), 3-9.

Cantú-Chapa, A., 1971, La Serie Huasteca (Jurásico Medio-Superior) del Centro-Este de México: Revista del Instituto Mexicano del Petróleo, 3(2), 17-40.

Cantú-Chapa, A., 1979, Bioestratigrafía de la Serie Huasteca (Jurásico Medio y Superior) en el subsuelo de Poza Rica, Veracruz: Revista del Instituto Mexicano del Petróleo, $11,14-24$.

Cantú-Chapa, A., 1980, El límite JurásicoCretácico en México, en Actas de II Congreso Argentino de Paleontología y Bioestratigrafía y I Congreso Latinoamericano de Paleontología, Asociación Paleontológica Argentina, 177-184.

Cantú-Chapa, A., 1984, El Jurásico Superior de Tamán, San Luis Potosí, Este de México, en Perrilliat, M.C. (ed.), Memoria III Congreso
Latinoamericano de Paleontología: Oaxtepec, Morelos, México, 207-215.

Callomon, J.H., 1992, Upper Jurassic, especially Mexico, en Westermann, G.E.G. (ed.), The Jurassic of the Circum Pacific: New York, Cambridge University Press, 261-272.

Cobiella-Reguera, J.L., Olóriz, F., 2009, Oxfordian-Berriasian stratigraphy of the North American paleomargin in western Cuba: Constraints for the geological history of the proto-Caribbean and the early Gulf of Mexico, en Bartolini, G., Román Ramos, J.R. (eds.), Petroleum systems in the southern Gulf of Mexico: American Association of Petroleum Geologist Memoir 90, 421-451.

Córdoba-Méndez, 1964, Geology of Apizolaya Quadrangle (D.A., East Half), Northern Zacatecas, Mexico: Texas, Faculty of the Graduate School of The University of Texas, Tesis de Maestría, 111 p.

Cooper, O., 1997, Articulate brachiopod shellbeds:

Silurian examples from Anticosti, Eastern Canada: GEOBIOS, 20, 133-148.

Dattilo, B.F., Brett, G.E., Schramm, T.J., 2012, Tempestites in a Teapot? CondensationGenerated Shell Beds in the Upper Ordovician, Cincinnati Arch, USA: Palaeogeography, Palaeoclimatology, Palaeoecology, 367/368, 44-62.

Davies, D.J., Powell, E.N., Stanton, R.J., 1989, Taphonomic signature as a function of environmental process. shells and shell beds in a hurricane-influenced inlet on the Texas Coast: Palaeogeography, Palaeoclimatology; Palaeoecology, 72, 317-356.

Del Castillo, A., Aguilera, J., 1895, Fauna fósil de la Sierra de Catorce: Boletín de la Comisión Geológica de México, 1, 55 p.

De La Mora, A., 1998, Análisis tafonómico e interpretaciones paleoecológicas del bentos en una sucesión del Jurásico Superior (Kimmeridgiano-Tithoniano) del área de Mazapil, Zacatecas: México, Universidad Nacional Autónoma de México, Tesis Maestría, $154 \mathrm{p}$. 
De La Mora, A., Olóriz, F., González-Arreola, C., 1999a, Datos preliminaries sobre el megabentos de bivalvos del Jurásico Superior-Cretácico basal en el Cañón de San Matías (Zacatecas, México): Geogaceta, 26, 19-22.

De La Mora, A., Olóriz, F., González-Arreola, C., Villaseñor, A.B., 1999b, Using bivalve assemblages for reconstruction of depositional conditions in fine-grained deposits from the Upper Jurassic of Mexico. Abstracts European Paleontological Association Workshop, Lisboa, 137-141.

De La Mora, A., Olóriz, F., González-Arreola, C., 2000, "Autochthonous" bivalve assemblages and palaeoecologic interpretation in the Upper Jurassic-Lowermost Cretaceous La Caja Formation from the Cañón de San Matías (Zacatecas, México): Comptes Rendus de l'Académie des Sciences - Series IIA - Earth and Planetary Science, 331, 741-747.

Eguiluz de Antuñano, S., Olivares-Ramos, D., López-Martínez, R., 2012, Discordancia entre el Jurásico y Gretácico en Huizachal, Tamaulipas, México: Su posible correlación con un límite de secuencia global: Revista Mexicana de Ciencias Geológicas, 29(1), 87-102.

Fernández-López, S., 1984, Nuevas perspectivas de la tafonomía evolutiva: tafosistemas y asociaciones conservadas: Estudios Geológicos, 40, 215-224.

Fernández-López, S., Gómez, JJ., 1991, Condensación: significados y aplicaciones al análisis de cuencas: Estudios Geológicos, 47, 169-181.

Fürsich, F.T., 1978, The influence of faunal condensation and mixing on the preservation of fossil benthic communities: Lethaia, 11, 243-250.

Fürsich, F.T., Oschmann, W., 1993, Shell beds as tools in basin analysis: the Jurassic of Kachchh, western India: Journal of the Geological Society, 150, 169-185.
Goldhammer, R.K., 1999, Mesozoic sequence stratigraphy and paleogeographic evolution of northern Mexico, en Bartolini, C., Wilson, J.L., Lawton, T.F. (eds.), Mesozoic sedimentary and tectonic history of northcentral Mexico: Geological Society of America Special Paper, 340, 1-58.

Goldhammer, R.K., Lehmann, P.J., Todd, R.G., Wilson, J.L., Ward, W.C., Johnson, C.R., 1991, Sequence stratigraphy and cyclostratigraphy of the Mesozoic of the Sierra Madre Oriental, Northeastern Mexico, a field guidebook: Gulf Cost Section, Society for Sedimentary Geology (SEPM), 85 p.

Gómez, J.J., Fernández-López, S., 1994, Condensation processes in shallow platforms: Sedimentary Geology, 92, 147-159.

González-Arreola, C., Olóriz, F., Villaseñor, A.B., Lara, L., 1992, Precisiones bioestratigráficas sobre la Formación Taraises en el área tipo (Sierra de Parras, Coahuila, México), (resumen), en Civis-Llovera, J., SierroSánchez, FJ., Sánchez de Posada, L.C. (eds.), III Congreso Geológico de España y VIII Congreso Latinoamericano de Geología: Salamanca, España, 260-265.

González-Sánchez, F., Puente-Solís, R., GonzálezPartida, E., Camprubí, A., 2007, Estratigrafía del Noreste de México y su relación con los yacimientos estratoligados de fluorita, barita, celestina y Zn-Pb: Boletín de la Sociedad Geológica Mexicana, 49(1), 43-62.

Hantzpergue, P., Atrops, F., Enay, R., 1997, Kimmeridgien, en Cariou, E., Hanzpergue, P. (eds.), Biostratigraphie du Jurassique Ouest-Européen et Méditerranéen: Groupe Français d'étude du Jurassique, Éditeur scientifique Bulletin des Centres de recherches exploration-production ElfAquitaine, Mémoire 17, 87-96.

Hara, U., Taylor, P.D., 2009, Cyclostome bryozoans from the Kimmeridgian (Upper Jurassic) of Poland: Geodiversitas, 31(3), 555-575.

Hewitt, R.A., Yoshiike, T., Westerman, G.E.G., 1991, Shell microstructure and ecology of 
the Cretaceous coleoid cephalopod Naefia from the Santonian of Japan: Cretaceous Research, 12, 47-54.

Imlay, R.W., 1938, Studies of Mexican Geosyncline: Bulletin of the Geological Society of America, 49, 1651-1694.

Imlay, R.W., 1939, Upper Jurassic Ammonites from Mexico: Bulletin of the Geological Society of America, 50, 1-78.

Imlay, R.W., 1941, Jurassic Fossils from Arkansas, Lousiana and Eastern Texas: Journal of Paleontology, 15, 3, 256-277.

Jank, M., Wetzel, A., Meyer, Ch.A., 2006, Late Jurassic sea-level fluctuations in NW Switzerland (Late Oxfordian to Late Kimmeridgian): closing the gap between the Boreal and Tethyan realm in Western Europe: Facies, 52, 487-519.

Kidwell, S.M., 1986, Models for fossil concentrations: paleobiological implications: Paleobiology, 12, 6-24.

Kidwell, S.M., 1991, The stratigraphy of shell concentrations, en Allison, P.A., Brigss, D.E.G. (eds.), Taphonomy. Releasing the data locked in the fossil record: Topics in Geobiology (9), New York., Plenum Press, 211-290.

Kidwell, S.M., Aigner, T., 1985, Sedimentary dynamics of complex shell beds. Implications for ecologic and evolutionary patterns, en Bayer, U., Seilacher, A. (eds.), Sedimentary and Evolutionary Cycles: Berlin, SpringerVerlag, 382-395.

Kidwell, S.M., Bosence, D.W.J., 1991, Taphonomy and Time-Averaging of Marine Shelly Faunas, en Allison, P.A., Briggs, D.E.G., Taphonomy: Releasing the Data Locked in the Fossil Record. Topics in Geobiology 9, Chapter 4, Plenum Press, New York, 116-209,

Kidwell, S.M., Fürsich, F.T., Aigner, T., 1986, Conceptual framework for the analysis and classification of fossil concentrations: Palaios, 1, 228-238.

Longoria, J.F., 1984, Stratigraphic studies in the Jurassic of Northeastern Mexico: Evidence for the origin of the Sabinas Basin, en Ventress, W.P.S., Bebout, D.G., Perkins, B.F., Moore, C.H. (eds.), The Jurassic of the Gulf Rim, GCSSEPM Foundation, Third Annual Research Conference Proceedings, 171-193. Lara-Morales, L., 1994, Revisión del género Idoceras Burckhardt, 1906 (Ammonitina), Análisis numéricos e interpretaciones paleobiológicas: México, Universidad Nacional Autónoma de México, Facultad de Ciencias, Tesis Maestría, 122 p.

López-Caballero, G.I., 2009, Bioestratigrafía

y Tafonomía de la sección estratigráfica Puerto Piñones (Jurásico Superior) del área de Saltillo, Coahuila, México. Universidad Nacional Autónoma de México, Posgrado en Ciencias de la Tierra, Tesis de Maestría, 168 p.

López-Palomino, I., 2015, Formación La Caja. Léxico Estratigráfico de México, Servicio Geológico Mexicano, 4 p.

López-Palomino, I., Villaseñor, A.B., Olóriz, F., 2006, Primer registro del género Vinalesphinctes (Ammonitina) en el Oxfordiano de México: Significación bioestratigráfica y consideraciones paleobiogeográficas en el Jurásico Superior de América: Revista Mexicana de Ciencias Geológicas, 23(2), 162-183.

Martini, M., Ortega-Gutiérrez, F., 2016, Tectono-stratigraphic evolution of eastern Mexico during the break-up of Pangea: A review, Earth Science Review, https://doi. org/10.1016/j.earscirev.2016.06.013.

Michalzik, D., 1988, Trias bis tiefste Unter-Kreide der Nordostlichen Sierra Madre Oriental, Mexiko- Fazielle Entwicklung einges passiven Kontinental randes, Technischen Hochshule Darmstadt, Darmstadt, Alemania, Tesis Doctorado, 247 p.

Michalzik, D., Schumann, D., 1994, Lithofacies relations and palaeoecology of a Late Jurassic to Early Cretaceous fan delta to shelf depositional system in the Sierra Madre Oriental of north-east Mexico: 
Sedimentology, 41, 463-477.

Moliner, L., Olóriz, F., Villaseñor, A.B., 2016, Ataxioceras (Ataxioceras) lopeztichae CantúChapa, 1991: Updating the systematic and palaeobiogeographic interpretation: Palaeontologia Electronica 19.2.19A: 1-16 palaeo-electronica.org/content/2016/1485ammonites-kimmeridgian-mexico.

Myczyński, R., Olóriz, F., Villaseñor, A.B., 1998, Revised biostratigraphy and correlations of the middle-upper Oxfordian in the Americas (Southern USA, Mexico, Guba and Northern Chile): Neues Jahrbuch für Mineralogie, Geologie und Paläontologie, Abhandlungen, 207(2), 185-206.

Nieto-Samaniego, A.F., Alaníz-Álvarez, S.A., Campubrí í Cano, A., 2005, La Mesa Central del México: Estratigrafia, Estructura y evolución tectónica Cenozoica: Boletín de la Sociedad Geológica Mexicana, 57(3), 285-318.

Olóriz, F., 1987, El significado biogeográfico de las plataformas mexicanas en el Jurásico Superior. Consideraciones sobre un modelo eco-evolutivo: Revista de la Sociedad Mexicana de Paleontología, 1(1), 219-247.

Olóriz, F., 1992, Northcentral and eastern Mexico, en Westermann, G.E.G. (ed.), The Jurassic of the Circum Pacific: New York, Cambridge University Press, 93-121.

Olóriz, F., Villaseñor, A.B., 2017, New species of Lower Tithonian macroconchiate Hybonoticeras from Mexico and the cooccurrence of Mazapilites and Hybonoticeras in the Mexico-Caribbean area: Journal of Paleontology [in press].

Olóriz, F., López-Galindo, A., Villaseñor, A B., González-Arreola, C., 1988, Análisis isotópicos y consideraciones paleoecológicas en el Jurásico Superior de México (Fm. La Casita, Cuencamé, Durango). Datos preliminares. Comunicaciones 1, II Congreso geológico de España, 144-148.

Olóriz, F., Villaseñor, A.B., González-Arreola, G., Westermann, G.E.G., 1990, Las plataformas mexicanas durante el Jurásico Superior. Un ejemplo de áreas de recepción en biogeografía. Actas de Paleontología, IV Jornadas de Paleontología, Salamanca, 68, 277-287.

Olóriz, F., Lara, L., De La Mora, A., Villaseñor, A.B., González-Arreola, C., 1993, The Kimmeridgian/Tithonian boundary in the "Barranquito del Alacrán" section at Cuencamé (Durango, Mexico); its biostratigraphy and ecostratigraphic interpretation: Acta Geologica Polonica, 43, 273-288.

Olóriz, F., Villaseñor, A.B., González-Arreola, C., Westermann, G.E.G., 1996, Ammonite biostratigraphy and correlations in the Upper Jurassic-Lowermost Cretaceous La Caja Formation of North-Central Mexico (Sierra de Catorce, San Luis Potosi) Abstracts, en Olóriz, F., Rodríguez-Tovar, FJ. (eds.), IV International Symposium Cephalopods Present and Past: Granada, Spain, 134-136.

Olóriz, F., Villaseñor, A.B., González-Arreola, C., 1997, Factors controlling upper Jurassic ammonite assemblages in north-central Mexico: Lethaia, 30, 337-351.

Olóriz, F., Villaseñor, A.B., González-Arreola, C., 1998, Re-evaluation of Procraspedites Spath, 1930 (ammonitina) from the upper Kimmeridgian of Mexico: Bulletin de la Société Gélogique de France, 169(22), 243-254.

Olóriz, F., Villaseñor, A.B., González-Arreola, C., Westermann, G.E.G., 1999, Ammonite biostratigraphy and correlations in the late Jurassic- earliest Cretaceous La Caja Formation of north-central Mexico. (Sierra de Catorce, San Luis Potosí), en Olóriz, F., Rodríguez-Tovar, F.J. (eds.), Advancing Research in Living and Fossil Cephalopods: New York, Plenum Press, 463-492.

Olóriz, F., Villaseñor, A.B., González-Arreola, C., 2000, Geographic control on phenotype expression. The case of Hybonoticeras mundulum (Oppel) from the Mexican Altiplano: Lethaia, 


\section{3, 157-174.}

Olóriz, F., Palmqvist, P., Pérez-Claros, J.A., 2002a, Morphostructural constraints and phylogenetic overprint on sutural frilling in Late Jurassic ammonites: Lethaia, 35, 158-168.

Olóriz, F., Reolid, M., Rodríguez-Tovar, F.J., 2002b, Fossil assemblages, lithofacies and taphofacies for interpreting depositional dynamics in epi-continental Oxfordian (Prebetic Zone, Betic Cordillera, southern Spain): Palaeogeography, Palaeoclimatology, Palaeoecology, 185, 53-75.

Olóriz, F., Villaseñor, A.B., Aranda-Manteca, F.J., 2003a, The co-occurrence of a Late Jurassic Ichthyosaurian reptile and ammonites in Durango, Mexico. Preliminary report on taphonomy, systematics and biochronology, Abstracts, in 99th Annual Meeting of the Geological Society of America, Puerto Vallarta, México, 194.

Olóriz, F., Villaseñor, A.B., González-Arreola, G., 2003b, Major lithostratigraphic units in landoutcrops of north-central Mexico and the subsurface along the northern rim of Gulf of Mexico Basin (Upper Jurassic-lowermost Cretaceous), a proposal for correlation of tectono-eustatic sequences: Journal of South American Earth Sciences, 16, 119-142.

Olóriz, F., Villaseñor, A.B., López-Palomino, I., 2008, Middle Oxfordian ammonite biostratigraphy of the Lower Santiago Formation at Tamán, San Luis Potosí, Mexico - with notes on Mexico-Caribbean ochetoceratins: Revista Mexicana de Ciencias Geológicas, 25(2), 261-283.

Omaña, L., Centeno-García, E., Buitrón-Sánchez, B.E., 2012, Comunidades bentónicas de plataformas del cretácico asociadas a arcos magmáticos en la parte occidental de México: Paleontología Mexicana, 62, 121-132.

Padilla y Sánchez, R.J., 1982, Geologic evolution of the Sierra Madre Oriental between Linares, Concepcion del Oro, Saltillo, and Monterrey, Mexico: The University of Texas at Austin, Tesis de Doctorado, $217 \mathrm{p}$.

Padilla y Sánchez, R.J., 1986, Post-Paleozoic tectonics of Northeast Mexico and its role in the evolution of the Gulf of Mexico: Geofísica Internacional, 25(1), 157-206.

Padilla y Sánchez, R.J., 2007, Evolución geológica del sureste mexicano desde el Mesozoico al presente en el contexto regional del Golfo de México: Boletín de la Sociedad Geológica Mexicana, 49(1), 19-42.

Pessagno, E.A.Jr., Martin, G., 2003, Tectonostratigraphic evidence for the origin of the Gulf of Mexico, en Bartolini, C., Buffler, R.T., Blickwede, J. (eds.), The Circum-Gulf of Mexico and Caribbean. Hydrocarbon habitats, basin formation and plate tectonics: American Association of Petroleum Geologist Memoir, 79, 46-74.

Pessagno, E.A.Jr., Hull, D.M., Martin, C.B., Meng, X., Montgomery, H., Ogg, J.G., UrrutiaFucugauchi, J., 1999, Stratigraphic evidence for northwest to southeast tectonic transport of Jurassic terranes in Central Mexico and the Caribbean (western Cuba), en Mann, P. (ed.), Caribbean Sedimentary Basins: Sedimentary Basins of the World, 4, 123-150.

Rogers, C.L., de Cserna, Z., Ojeda, R.J., Tavera, A. E., Van Vloten, R., 1961, Reconocimiento geológico y depósitos de fosfatos del Norte de Zacatecas y Áreas Adyacentes en Coahuila, Nuevo León y San Luis Potosí: Consejo de Recursos Naturales No Renovables, Boletín, 56.

Rogers, R.R., Kidwell, S.M., 2007, A conceptual framework for the genesis and analysis of vertebrate skeletal concentrations, en Rogers, R.R., Eberth. D.A., Fiorillo, A.R. (eds.), Bonebeds -Genesis, Analysis and Paleobiological Significance: Chicago, London, The University of Chicago Press, $1-65$.

Salvador, A., 1991, Triassic-Jurassic, en Salvador, A. (ed.), The Gulf of Mexico Basin, The Geology of North America, Journal Geological Society of America, Boulder, 
Colorado, 131-180.

Schumann, D., 1985, Environment and postmortem History of Upper Jurassic ammonites in Nuevo León, NE Mexico, en Wiedmann, J., Kullman, J. (eds.), Cephalopods Past and Present, O.H. Schindewolf-Symposium Tübingen, 2nd International Cephalopod Symposium: Stuttgart, E. Schweizerbart'sche Verlagsbuchhandlung (Nägele und Obermiller), 731-736.

Schumann, D., 1988, Observaciones paleoecológicas en secuencias del Kimmeridgiano/Tithoniano (Formación La Casita) de Nuevo León, Noreste de México: Actas de la Facultad de Ciencias de la Tierra, Universidad Autónoma de Nuevo León, 3, 43-59.

Seilacher, A., 1982, General remarks about event deposits, en Einsele, G., Seilacher, A. (eds.), Cyclic and Event Stratification, SpringerVerlag, New York, 161-174.

Velasco-Segura, J., 2005, Análisis litológico y estratigráfico de la Formación La Caja en la 'Sierra el Jabalí', Saltillo, Coahuila, México, Facultad de Ciencias de la Tierra, Universidad Autónoma de Nuevo León, Tesis de Licenciatura, $142 \mathrm{p}$.

Verma, H.M., Westermann, G.E.G., 1973, The Tithonian (Jurassic) ammonite fauna and Stratigraphy of Sierra Catorce, San Luis Potosí, Mexico: Bulletins of American Paleontology, 63, 227, 108-137.

Villaseñor, A.B., 1991, Aportaciones a la bioestratigrafía, basada en la fauna de ammonites de la sucesión del Jurásico Superior (Kimmeridgiano-Tithoniano) del área de Mazapil, Zacatecas, México: México, Universidad Nacional Autónoma de México, Facultad de Ciencias, Tesis de Doctorado, $156 \mathrm{p}$.

Villaseñor, A.B., Olóriz, F., 2009, Caribbean Lower Tithonian ammonites from centraleast Mexico, Ammonites des Caraibes dans le Tithonien inférieur du centre-est du Mexique: Geobios, 42, 117-132.
Villaseñor, A.B., Olóriz, F., González-Arreola, C., 1991, Las plataformas marinas del Jurásico Superior en el área de Sierra de Catorce, Estado de San Luis Potosí, una aproximación a la interpretación ecoestratigráfica, en Rubinovich, R., Carreño, A.L. (eds.), Memoria de la Primera Convención sobre la Evolución Geológica de México, 238-240, Pachuca, Hidalgo, México.

Villaseñor, A.B., Olóriz, F., De La Mora, A., 1995, Consideraciones sobre el registro del género Hybonoticeras (Ammonitina) en México, en Villaseñor, A.B., De la Mora, M.A. (eds), Memoria de resúmenes del $\mathrm{V}$ Congreso Nacional de Paleontología, 46-47, México, D.F., México.

Villaseñor, A.B., Olóriz, F., González-Arreola, C., 2000, Recent Advances in Upper Jurassic (Kimmeridgian-Tithonian) Ammonite Biostratigraphy of North-Central Mexico Based on Recently Collected Ammonite Assemblages: GeoResearch Forum, 6, 249-262.

Villaseñor, A.B., Olóriz, F., López-Palomino, I., López-Caballero, I., 2012, Updated ammonite biostratigraphy from upper Jurassic deposits in Mexico: Revue de Paléobiologie, Volume spéciel, 11, 249-267.

Villaseñor, A.B., Moliner, L., Olóriz, F., 2015, Schneidia zacatense sp. nov. -First population level study of Ataxioceratinae from the Lower Kimmeridgian in northern Mexico - Biostratigraphic and palaeobiogeographic significance: Journal of South American Earth Sciences, 63, 217-243.

Westermann, G.E.G., 1982, The connecting rings of Nautilus and Mesozoic ammonoids: implications for ammonoid bathymetry: Lethaia, 15, 373-384.

Wierzbowski, A., Atrops, F., Grabowski, J. Hounslow, M., Matyja, B.A., Olóriz, F., Page, K., Parent, H., Rogov, M.A., Schweigert, G., Villaseñor, A.B., Wierzbowski, H., Wright, J.K., 2016, Towards a consistent OxfordianKimmeridgian global boundary: current 
state of knowledge: Volumina Jurassica, 14, $15-50$.

Wright, V.P., 1992, A revised classification of limestones: Sedimentary Geology, 76, 177-186.

Zell, P., Stinnesbeck, W., 2016, Paleobiology of the Latest Tithonian (Late Jurassic) Ammonite Salinites grossicostatum Inferred from Internal and External Shell Parameters: PlosOne, 56, 91-109.

Zell, P., Beckmann, S., Stinnesbeck, W., 2013, Late Jurassic-earliest Cretaceous belemnites (Cephalopoda: Coleoidea) from northeastern Mexico and their palaeobiogeographic implications: Neues Jahrbuch für Geologie und Paläontologie Abhandlungen, 270(3), 325-341.

Zell, P., Beckmann, S., Stinnesbeck, W., 2014, Age and depositional conditions of the marine vertebrate concentration Lagerstätte at Gomez Farías, southern Coahuila, Mexico: Journal of South American Earth Sciences, 56, 91-109.

Zell, P., Stinnesbeck, W., Hering, F., 2016, A coralrich unit of Berriasian (Early Cretaceous) age in the Sierra Madre Oriental of northeastern Mexico: Journal of South American Earth Sciences, 69, 91-102. 